\title{
The Development of Silicon Nanowire as Sensing Material and Its Applications
}

\author{
Jahwarhar Izuan Abdul Rashid, ${ }^{1,2}$ Jaafar Abdullah, ${ }^{3}$ Nor Azah Yusof, ${ }^{1,3}$ and Reza Hajian ${ }^{1}$ \\ ${ }^{1}$ Functional Devices Laboratory, Institute of Advanced Technology, Universiti Putra Malaysia (UPM), 43400 Serdang, \\ Selangor, Malaysia \\ ${ }^{2}$ Department of Chemistry and Biology, Centre for Defense Foundation Studies, National Defense University of Malaysia, \\ Sungai Besi Camp, 57000 Kuala Lumpur, Malaysia \\ ${ }^{3}$ Department of Chemistry, Faculty of Science, Universiti Putra Malaysia (UPM), 43400 Serdang, Selangor, Malaysia
}

Correspondence should be addressed to Nor Azah Yusof; azahy@upm.edu.my and Reza Hajian; rezahajian@putra.upm.edu.my

Received 4 September 2013; Accepted 3 November 2013

Academic Editor: Artde Donald Kin-Tak Lam

Copyright (c) 2013 Jahwarhar Izuan Abdul Rashid et al. This is an open access article distributed under the Creative Commons Attribution License, which permits unrestricted use, distribution, and reproduction in any medium, provided the original work is properly cited.

\begin{abstract}
The application of silicon nanowire (SiNW) as a sensing nanomaterial for detection of biological and chemical species has gained attention due to its unique properties. In this review, a short description is also demonstrated on the synthesis techniques of SiNWs and recent progress on sensor development based on electrochemical methods, fluorescence field-effect transistors (FET), and surface-enhanced Raman scattering (SERS) spectroscopy. We also discussed the challenges of SiNW-based sensors in the future.
\end{abstract}

\section{Introduction}

In the last decades, biological and chemical sensor technologies have received a tremendous interest among research areas in various applications due to their efficiency in monitoring and regulating many areas such as toxicology testing $[1,2]$, food industry $[3,4]$, medical diagnostics [5$7]$, environmental monitoring $[8,9]$, and drug industries $[10,11]$. Biosensors or chemical sensors can be defined as analytical devices that incorporated with sensing materials and molecular recognition elements (enzyme, protein, antibody, nucleic acid, hormone, chemical compounds, etc.) that get integrated within transducers [12-16]. The basic principle of sensor detection is based on interaction between the recognition molecule (biological or chemical molecule) and its target, and the change of the biochemical reaction would be catalyzed by the sensing material as well as translated into a quantifiable signal via the transducer, whether in the form of electrochemical [17, 18], electrical [19], optical [20], piezoelectric [21], thermometric [22], and so forth. The important criterion in the construction of sensors is the performance, in terms of sensitivity, that is able to achieve low detection limits. Hence, the choice of the sensing material is the fundamental prerequisite step in the development of ultrasensitive sensors [23, 24].

With the fast growth and development of advanced nanotechnology, many sensing nanomaterials with unique properties, desired size, and chemical compositions have been fabricated to be incorporated within the transducer. One of them is the application of one-dimensional (1D) nanostructures (nanotubes, nanowires, nanorods, nanobelts and heteronanowires) within the transducers in previous studies that can enhance the sensor performance, for example, $\mathrm{TiO}_{2}$ nanowires [25], carbon nanotubes [26], CuS nanowires [27], $\mathrm{NiO}-\mathrm{Au}$ nanobelts [28], CuS nanotubes [27], and graphene oxide-modified vanadium nanoribbons [29].

Silicon nanowire is one of the 1D nanostructures and has emerged as the promising sensing nanomaterial upon its unique mechanical, electronical, and optical properties [3034]. The main reason why SiNWs have attracted attention in the development of ultrasensitive sensors is due to their high surface to volume ratios $[35,36]$ thus greatly enhancing the detection limit to $\mathrm{fM}$ concentrations and giving high sensitivity. In addition, the dimension of SiNW is in the range of $\approx 1-100 \mathrm{~nm}$, hence making it very comparable and compatible 


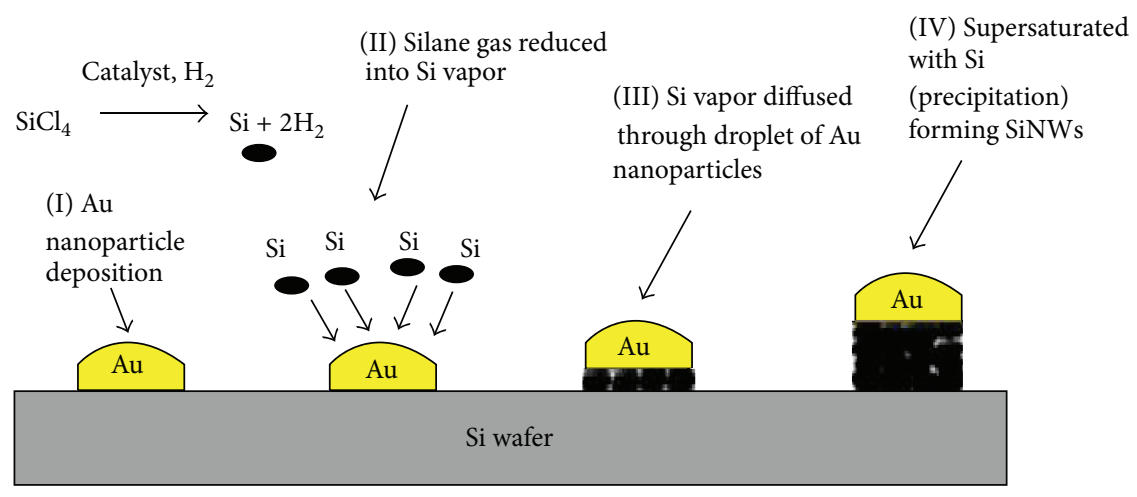

FIgURE 1: The SiNWs synthesis using VLS method via CVD method.

to the dimensional scale of biological and chemical species $[37,38]$. Having the smallest dimension, SiNWs exhibited good electron transfer in detection because the accumulation of charge in SiNWs directly occurs within the bulk of material resulting in fast response of detection. In this review, we briefly elaborate on the synthesis of silicon nanowires and the application of chemical and biological sensors based on SiNWs.

\section{SiNWs Synthesis Techniques}

In general, two techniques have been developed for fabrication of SiNWs such as bottom-up approach (Vapour liquid solid (VLS), oxide assisted growth (OAG), and metal assisted chemical etching) and top-down approach. Bottomup method is a growth or synthesized technique of the SiNWs from bulk silicon wafer either metal catalyzed-assisted or metal catalyzed-free. Meanwhile, top-down approach starts from bulk silicon wafer and scales down to the desired size and shape of SiNWs using a lithographic process.

2.1. Vapour Liquid Solid (VLS). Wagner and Ellis have reported for the first time silicon wire synthesis in vapor phase condition using silicon substrate coated with liquid $\mathrm{Au}$ droplet [39]. In VLS, metal-catalyzed ( $\mathrm{Au}, \mathrm{Fe}, \mathrm{Pt}, \mathrm{Al}$, etc.) would be deposited on the silicon wafer first and then the SiNWs growth is enhanced either by chemical vapor deposition (CVD) technique [40-42] or by laser ablation methods [43]. Principally, Si wafer coated metal catalysts are placed at the center of the horizontal tube furnace and introduced with a $\mathrm{Si}$ gas source such as silane $\left(\mathrm{SiH}_{4}\right)$ or tetrachlorosilane $\left(\mathrm{SiCl}_{4}\right)$ and passed over metal catalyst deposited on Si wafer in the chamber at above eutectic temperature [44]. The silane $\left(\mathrm{SiH}_{4}\right)$ gas would be decomposed into silicon vapor and diffuses through metal catalyst forming metal-silicon alloy droplets. As silicon diffuses through metal nanoparticle catalyst resulting in a supersaturate condition the silicon will precipitate out from droplets of metal-Si forming silicon nanowires [45]. With establishing a uniform distribution of metal nanoparticles catalyzed on the substrate, we can possibly manage to control the diameter and growth alignment of SiNWs (Figure 1).
2.2. Oxide Assisted Growth (OAG) via Thermal Evaporation. In recent years, many researchers have successfully fabricated SiNWs using bottom-up approach called oxide assisted growth $(\mathrm{OAG})$ via thermal evaporation due to its advantages in producing a large quantity of SiNWs [46-49]. In this OAG method, the growth of SiNWs was greatly enhanced using $\mathrm{SiO}$ as starting material to induce the nucleation and the growth of SiNWs without assisted catalyzed metal thus producing high purities SiNWs, free of metal contamination [50]. The fabrication of SiNWs using OAG method has been described in detail by the group of Shao et al. [50]. In their experiment, the alumina boat containing the mixture of $\mathrm{SiO}$ powder $(10 \mathrm{~g})$ and $\mathrm{Si}$ powder $(0.05 \mathrm{~g})$ was placed at the center of an alumina tube, inside horizontal tube furnace. With certain pressure, Argon as a carrier gas was introduced and the furnace heated to $1250-1300^{\circ} \mathrm{C}$ for 10 hours. SiNWs with diameter of $85 \mathrm{~nm}$ were collected around the alumina tube surface (Figure 2). One of the characteristics of SiNWs produced by OAG method is the presence of oxide layer at the outer surface of SiNWs which is chemically inert. This oxide layer was usually removed by treatment of hydrofluoric acid (HF) to improve the electrical and optical properties of SiNWs. According to Zhang et al. [51], the advantage of this method is capability to produce different morphologies in chains, rods, wires, ribbons and coaxial structures and the use of dangerous precursor gases such as silane $\left(\mathrm{SiH}_{4}\right)$ or tetrachlorosilane $\left(\mathrm{SiCl}_{4}\right)$ can be avoided. The main similarity between VLS and OAG methods is in the final SiNWs grown product in the form of suspended nanowires [52].

2.3. Metal Assisted Chemical Etching. Metal assisted chemical etching was reported as a low-cost and simple technique for SiNWs array fabrication [53]. This method involves two main steps which are electroless metal (silver, nickel, platinum, gold) deposition on silicon wafer followed by chemical etching in Fluoride-ion-based solution [54-56]. Simultaneous reaction of electroless deposition and chemical etching can be seen in the work of Brahiti et al. [57], when they soaked cleaned $\mathrm{Si}$ wafer in a solution containing $\mathrm{NH}_{4} \mathrm{HF}_{2}$ and $\mathrm{AgNO}_{3}$. In this process, $\mathrm{Ag}^{+}$ion would attract electrons from the silicon substrate (1) that resulted from deposition 


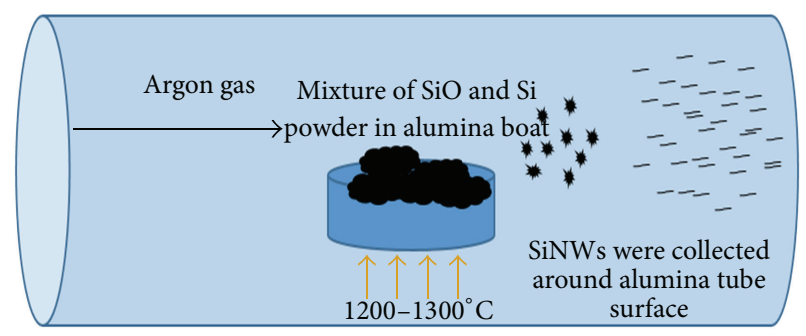

(a)

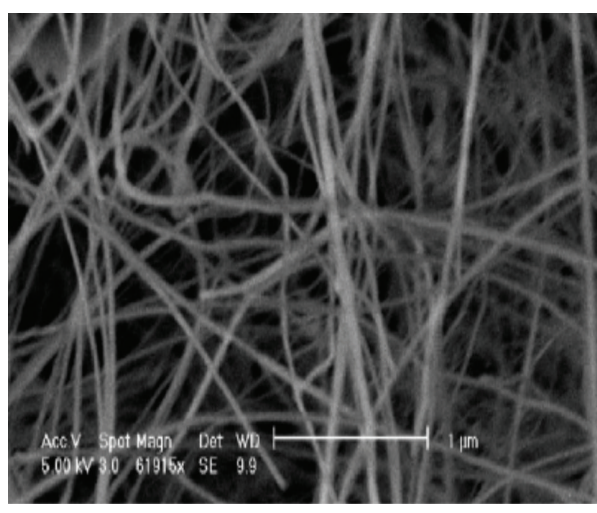

(b)

FIGURE 2: (a) Schematic diagram of synthesis SiNWs using OAG method; (b) SEM image of SiNWs synthesis using OAG method. (Reprinted with permission from [50].)

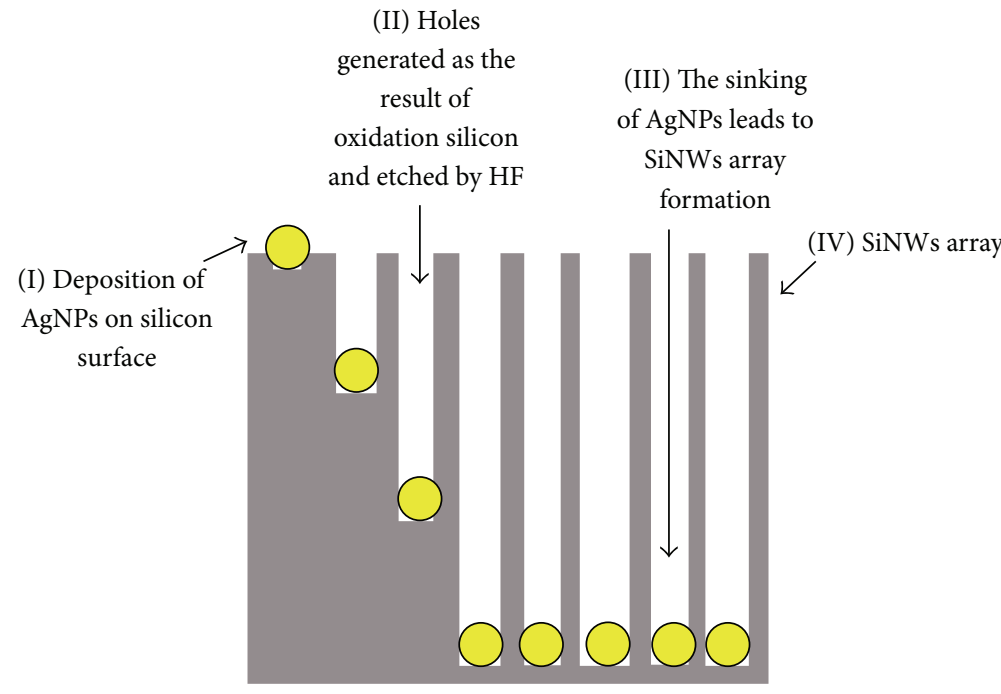

(a)

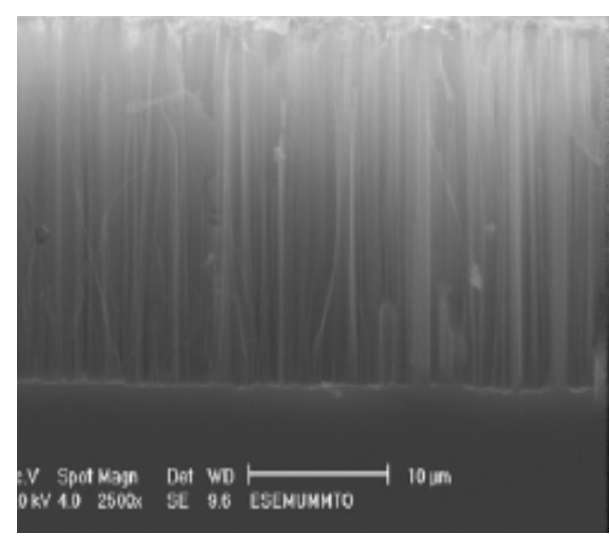

(b)

Figure 3: (a) Ag assisted chemical etching mechanism (b) view SEM image of Au-assisted electroless etched silicon in $15 \mathrm{~g} \mathrm{NH}_{4} \mathrm{HF}_{2} ; 40 \mathrm{~mL}^{\circ}$ $\mathrm{H}_{2} \mathrm{O}_{2} ; 50 \mathrm{~mL} \mathrm{H} \mathrm{H}_{2} \mathrm{O}$ solution of $\mathrm{pH}-1$ in room temperature for $30 \mathrm{~min}$. (Reprinted with permission from [59].)

of Ag nanoparticle on silicon surface as Si electronegativity is higher than silicon [58]. Consider

$$
\mathrm{Ag}+\mathrm{e}^{-} \longrightarrow \mathrm{Ag}^{0}(\mathrm{~s})
$$

Meanwhile, silicon beneath the Ag nanoparticle is oxidized and then etched by HF etchant causing the holes formation. The remaining of the Ag nanoparticles would sink into holes and longitudinal and lateral dissolution of silicon triggering the formation of SiNWs arrays [59] (Figure 3). According to Zhang et al. [60], different morphologies of SiNWs arrays could be obtained with the manipulation parameters of etching conditions (temperature, deposition time, and concentration etchant), surface orientation, and doping level.

2.4. Top-Down Approach. Generally, fabrication of SiNWs via a top-down approach which employed the application of advanced nanolithography tools on silicon-on insulator (SOI) is mostly compatible with conversional complementary metal oxide-semiconductor (CMOS) technology that typically consist of deposition, etching and patterning steps. Basically, the SiNWs fabrication started from the bulk material and scaled down into a single SiNW or SiNW array that can be formed with the help of nanolithography techniques such as electron beam lithography (EBL) [61], lithography patterned nanowires electrodeposition, nanoimprint lithography [62], and photolithography. For example, Park et al. [61] applied a top-down approach using electron beam lithography and reactive ion etching on SOI wafer producing high control of the geometry and alignment of SiNWs as well as showing good electrical properties. High arrays of SiNWs with width down to $20 \mathrm{~nm}$ and height of $60 \mathrm{~nm}$ have been demonstrated by the group of $\mathrm{Vu}$ et al. [62] which combined the attributes of the nanoimprint lithography and 


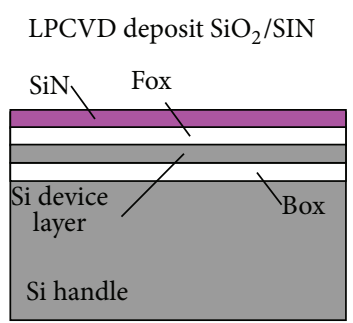

(a)

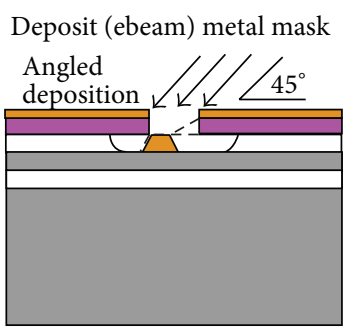

(d)

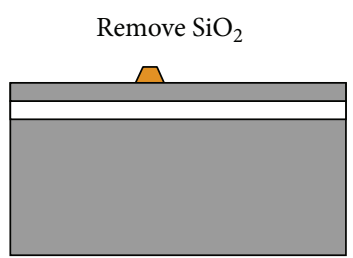

(g)
RIE SiN

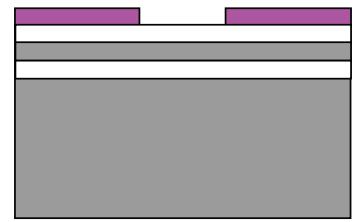

(b)

Ion beam milling metal mask

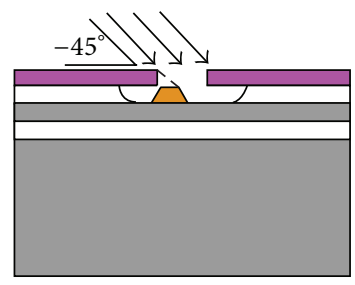

(e)

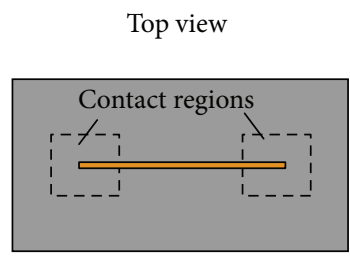

Top view

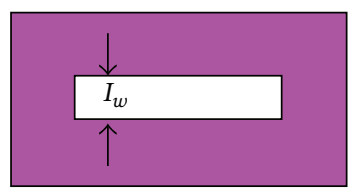

Remove SiN

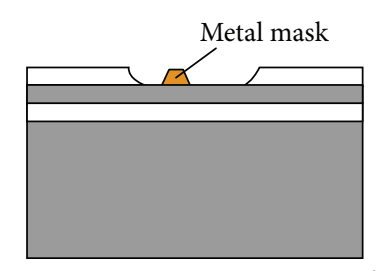

(f)

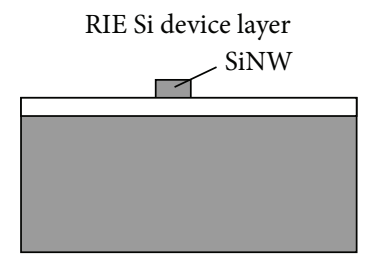

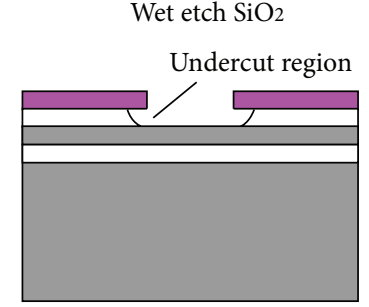

(c)

Top view

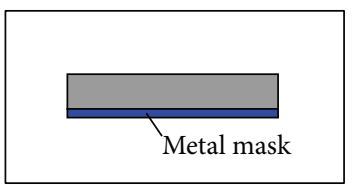

Top view

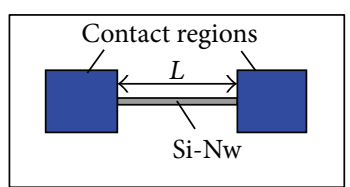

(h)

FIGURE 4: Single mask silicon nanowires DEA fabrication process. (Reprinted with permission from [63].)

TMAH wet anisotropic etching. Pham et al. [63] utilized the DEA technology and photolithography technique to realize a single SiNW with diameter below $100 \mathrm{~nm}$ and height of $1 \mathrm{~mm}$ (Figure 4). SiNW arrays which consist of 250 nanowires with $150 \mathrm{~nm}$ width, $20 \mu \mathrm{m}$ length, and equal space size of approximately $3.2 \mathrm{~nm}$ have been successfully fabricated by the group of Kulkarni et al. [64] using top-down approach. In their work, they approached 4 steps of photolithography techniques, deep reactive ion etching (DRIE), TMAH wet anisotropic etching, and thermal oxidation for development of SiNW FET sensor.

Tong et al. [65] presented a new low-cost, top-down nanowire fabrication technology without using nanolithography. This technique is suitable for any conventional microtechnology clean room facility. This novel wafer-scale technology process uses a combination of angled thin-film deposition and etching of a metal layer in a precisely defined cavity with a single micrometer-scale photolithography step. The key factor to provide an improved dimensional control compared to other methods is a precisely defined cavity that permits controlled removal of the metal layer with an angled wafer level ion beam that resembles a nanostencil structure patterned directly on the wafer surface, which minimizes lateral spread of the deposited metal.

Chen et al. [66] presented a new simple Si-NWs fabrication technology that requires only two microlithography steps and conventional microfabrication processes on silicon-on-insulator wafers to form long (ranging from a few micrometers up to $\approx 100 \mu \mathrm{m}$ ) Si-NWs with scalable lateral dimensions ranging from $200 \mathrm{~nm}$ down to $10-20 \mathrm{~nm}$ with near-perfect crystalline cross sections, atomically smooth surfaces, and wafer-scale yields greater than 90\% using a novel size reduction method where nanowires can be controllably scaled to any dimension and doping concentration, independent of large contacting regions, from a continuous layer of crystalline silicon.

In some circumstances, instead of the following "bottomup synthesis first, assembly and top-down fabrication next," it is desirable to grow nanowires precisely and rationally in a predetermined device architecture [67]. Direct integration of growth into fabrication will markedly simplify procedures and avoid deterioration of nanowires in some micro/nanofabrication processes. In the study reported by He et al. [68], Si nanowires have been grown laterally in microtrenches that were prefabricated on silicon-on-insulator wafers, which demonstrated that nanowire growth and device fabrication can be achieved simultaneously. Lateral bridging growth was first demonstrated for GaAs nanowires [69] and recently for Si nanowires [70]. However, well controlled growth and device operation were not achieved. He et al. demonstrated excellent epitaxial growth of bridging $\mathrm{Si}$ nanowires and effective control of diameters, lengths, and densities [68]. Table 1 shows a brief description on the SiNW synthesis as reported above. 
TABLE 1: SiNWs synthesis techniques.

\begin{tabular}{|c|c|c|c|}
\hline Technique & & Material & Reference \\
\hline \multirow{6}{*}{ Bottom-up approach } & \multirow{3}{*}{ Vapour liquid solid (VLS) } & Coating catalyzed metals on silicon substrate-CVD & {$[39-42]$} \\
\hline & & Coating catalyzed metals on silicon substrate-laser ablation & {$[43]$} \\
\hline & & Si wafer coated metal catalyst introduced with Si gas source & {$[44,45]$} \\
\hline & \multirow{2}{*}{ Oxide assisted growth (OAG) } & OAG-thermal evaporation & {$[46-50]$} \\
\hline & & OAG-HF & {$[51]$} \\
\hline & Metal assisted chemical etching & Electroless metal deposition-chemical etching & {$[54-60]$} \\
\hline \multirow{6}{*}{ Top-down approach } & & Electron beam lithography & [61] \\
\hline & & Nanoimprint lithography & {$[62]$} \\
\hline & & DEA technology and photolithography & {$[63]$} \\
\hline & & Photolithography-DRIE-TMAH-thermal oxidation & {$[64]$} \\
\hline & & Angled thin-film deposition-micrometer scale photolithography & {$[65]$} \\
\hline & & Lateral bridging growth & {$[70]$} \\
\hline
\end{tabular}

\section{Applications of SiNW-Based Sensor for Chemical and Biological Molecule Detection}

In this section, we demonstrate the latest applications of SiNW based sensor using different detection methods including surface-enhanced Raman scattering (SERS), fluorescence, electrochemical methods, and field-effect transistors (FET) that have been fabricated.

3.1. Surface-Enhanced Raman Scattering (SERS) Spectroscopy Sensor Utilized SiNWs. Surface-enhanced Raman scattering spectroscopy based on a metal nanostructure has gained attention due to the enhancement of Raman signal that reached $10^{12}-10^{15}$ compared to normal Raman signals. In recent years, most studies reported the utilization of SiNWs functionalized Ag nanoparticles to enhance SERS detection. Silver coated SiNW arrays are described as ultrasensitive SERS sensor for Amoxicillin (an antibiotic medicine that always exists in milk and dairy product) and calcium dipicolinate (CaDPA), marker compound of $B$. anthracis spore detection [71]. The author explained that silver coated SiNW arrays as SERS sensor are suitable to detect residual amoxicillin in the milk since they are capable of detecting the concentration down to $10^{-9} \mathrm{M}$. The developed sensor also could achieve detection limit of $4 \times 10^{-6} \mathrm{M}$ for calcium dipicolinate which is 15 times lower than an infectious dose of spore $\left(6 \times 10^{-5} \mathrm{M}\right)$ suggesting that it is extremely suitable for detecting $B$. anthracis spore. The authors further explored the application of SiNW arrays coated with Ag nanoparticle as SERS substrate for protein and immunoglobulin detection [72]. The results showed that Raman signals of $50 \mathrm{ng}$ mouse immunoglobulin $\mathrm{G}$ (migG) and 50 ng goat anti-mouse immunoglobulin $G$ (gamIgG) were effectively enhanced using SiNWs-AgNPs in different SERS substrates (silicon(III) wafer, SiNWs arrays, and Ag coated silicon wafer). Interestingly, when the concentration of immunoreagents (migG and gamIgG) was down to $10 \mathrm{ng}$, it produced weak Raman signals but in the presence of the same concentrations of migG-gamIgG complex the Raman signal is strong. This may be due to the fact that the immune reaction between migG and gamIgG changed the conformation structure in terms of amino acid residue, functional group, and orientation bonds thus displaying different Raman signals. The detection limit of $4 \mathrm{ng}$ immunocomplex is obtained using SiNWs-AgNPs as SERS substrate. Zhang et al. [72] concluded that each of the AgNPs that were distributed on the surface of the SiNWs produced the own electromagnetic wave and SiNWs played a role to transfer, couple, and resonate the entire surface of AgNPs/SiNWs which afforded a strong Raman signal.

Study of Shao et al. [50] also demonstrated good results for achieving high sensitivity for SERS sensor based on silicon nanowires decorated Ag nanoparticles approach to achieve detection limit of $25 \mu \mathrm{L}$ of $1 \times 10^{-16} \mathrm{M}, 1 \times 10^{-16} \mathrm{M}, 1 \times 10^{-14} \mathrm{M}$, and $1 \times 10^{-8} \mathrm{mg} / \mathrm{mL}$ for Rhodamine, crystal violet, nicotine in methanol, and calf thymus DNA, respectively. They also established inorganic ion $\mathrm{SO}_{4}{ }^{2-}$ SERS sensor using the same SiNWs-AgNPs nanomaterial which allowed detection limit of $1 \times 10^{-9} \mathrm{M}$. Furthermore, the group of Jiang et al. [73] have fabricated SiNW decorated AgNPs via metal assisted chemical etching technique based sandwich structural DNA SERS sensor for multiplex DNA detection. In their studies, they demonstrated the immobilization of thiolated singlestranded DNA probe functionalized with AgNPs via Ag$S$ bonding and followed by hybridization with the target reporter probe labeled with Rhodamine $6 \mathrm{G}$ before SERS detection (Figure 5). This remarkable strategy showed high reproducibility and specifically for DNA detection where this SERS sensor is capable of discriminating single base mismatched DNA at lower concentrations of $1 \mathrm{pM}$.

Han et al. [74] introduced the optimized single SiNWsAgNPs for SERS detection of pesticide residues (carbaryl) on cucumber surface which was featuring the advantages in terms of simplicity, flexibility, high resolution, in situ detection, fast response (within one second), and enhanced attachment of sensor on rough surface of probe. The authors also studied the detection of E. coli-based SERS sensor by assembling the AgNPs-SiNWs on the commercial filter as water contaminated with $E$. coli was filtered first before characterization by Raman spectroscopy (Figures 6(a) and $6(b))$. 


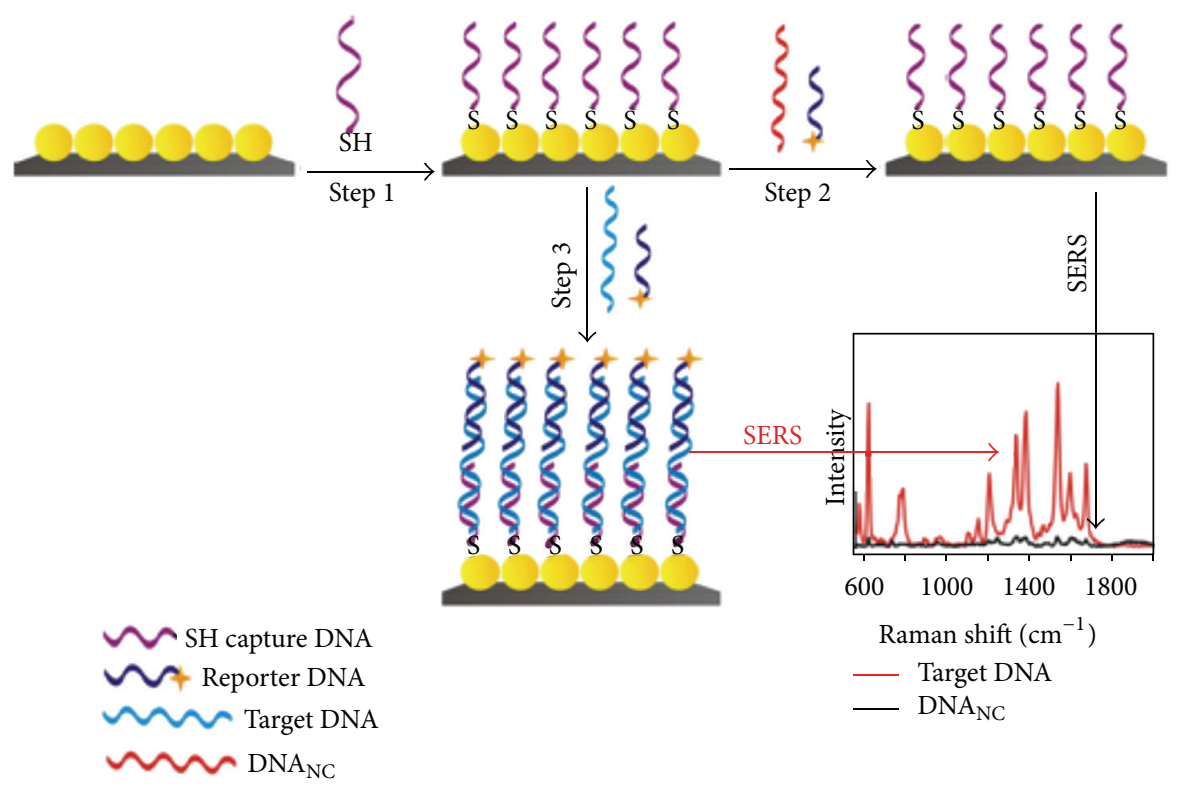

Figure 5: The development of SERS sensor based SiNWs/AgNPs for DNA detection. (Reprinted with permission from [73].)

3.2. Fluorescence's Sensor Utilized SiNWs. Su et al. [75] recently developed novel AuNP-SiNW-based molecular beacons (MBs) for high-sensitivity multiplex DNA detection (Figure 7). Interestingly, the authors found that AuNPsSiNWs based MBs showed robust stability in wide salt concentrations $(0.01-0.1 \mathrm{M})$ and thermal stability $\left(10^{\circ} \mathrm{C}-\right.$ $\left.80^{\circ} \mathrm{C}\right)$. AuNPs-MBs gradually aggregated due to salt induced reduction of electrostatic between AuNPs at the high concentration of salt [76]. In principle, both ends through the stem loop structured oligonucleotide were modified with organic dyes, carboxyfluorescein and thiol group, assembled at AuNPs/SiNWs via Au-S bonds. Since the position of carboxyfluoresceine is close proximity with AuNPs-SiNWs in terms of stem loop conformation structure, leading feeble intensity of fluorescence. When DNA hybridization happened, the stem loop of MBs underwent conformation changes resulting in spatial separation of the carboxyfluorescein and AuNPs-SiNWs, thus enhancing the fluorescence intensity. The study found that when the concentration of target DNA increased from $50 \mathrm{pM}$ to $10 \mathrm{nM}$, the fluorescence intensity was significantly enhanced. The authors concluded that AuNPs-SiNWs based on MBs are able to detect DNA target at low concentrations down to pM level and also show high selectivity in the presence of noncomplementary DNA and single base mismatch.

There is another research by Maxwell et al. [77], who designed a simple method of fluorescence detection for DNA hybridization events through fabrication of SiNW network modified DNA probe. The complementary target DNA labeled with a fluorescence dye, cyanine (Cy3), would hybridize with SiNW networks and detected using Olympus BX41M microscope. The authors made a comparison of three different regions of the sample (DNA-grafted SiNWsDNAgrafted $\mathrm{Si}_{3} \mathrm{~N}_{4}$ surface, $\mathrm{Si}_{3} \mathrm{~N}_{4}$ surface) and as expected the SiNW networks enhanced the fluorescence signal. It was found that the optical sensor has high selectivity as it has the lower fluorescence signal with no complementary DNA due to the absence of Cy3 labeled target DNA, which is more than 30 lower than complementary DNA.

Another application of SiNWs has been reported by Han et al. [78] for fluorescence protein immunosensor development. The authors reported the fabrication of verticallyaligned SiNW arrays ( $8 \mu \mathrm{m}$ in height and $150 \mu \mathrm{M}$ in diameter) via electroless etching (AEE) process and protein were covalently immobilized onto (aminopropyltriethoxysilane) APTES modified SiNWs. Due to the high aspect ratio of SiNWs generated high surface of SiNWs that enhanced the immobilization of loaded BSA protein, which is approximately 14 times $\left(57.33 \pm 4.76 \mu \mathrm{g} / \mathrm{cm}^{2}\right)$ more than planar silicon substrates $\left(4.10 \pm 4.76 \mu \mathrm{g} / \mathrm{cm}^{2}\right)$. Based on the positive result of BSA immobilization using modified SiNWs-BSA, the authors continued to construct two types of immunosensor assays between IgG and FITC-anti-Ig-G (Fluorescein isocyanate) and $\operatorname{IgM}$ and Cys3-anti $\operatorname{IgM}$. Their finding demonstrated that fluorescence intensity as the result of the binding of both anti-Ig $\mathrm{G}$ and anti-Ig $\mathrm{M}$ was greatly enhanced using SiNWs compared with planar substrates (Figure 8).

New type of optical sensor based on SiNWs for $\mathrm{Cu}$ (II) detection, an important element for hematopoiesis, metabolism, growth, and immune system, was constructed by the group of $\mathrm{Mu}$ et al. [79]. Here, the authors modified the surface of SiNWs via reaction of the outer hydroxyl group with silanol group of fluorescence ligand, N-(quinoline-8yl)-2(3-triethoxysilyl-propylamino)-acetamide (QIOEt) produced highly sensitive for $\mathrm{Cu}(\mathrm{II})$ detection down to $10^{-8} \mathrm{M}$, higher than unmodified with QIOEt. The presence of other metal ions such as mercury, zinc, cadmium, ferrum, cobalt, and plumbum in this study did not have significant interference effect on the selectivity of an optical sensor based on QIEOT-SiNWs. Miao et al. [80] reported the application of SiNWs in the development of fluorescence sensor for detection of nitride oxide (NO) from liver extract. It 
(a)

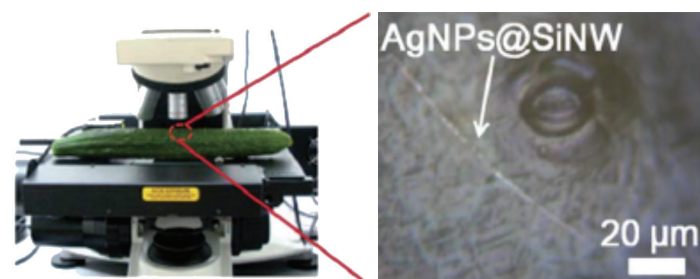

(b)

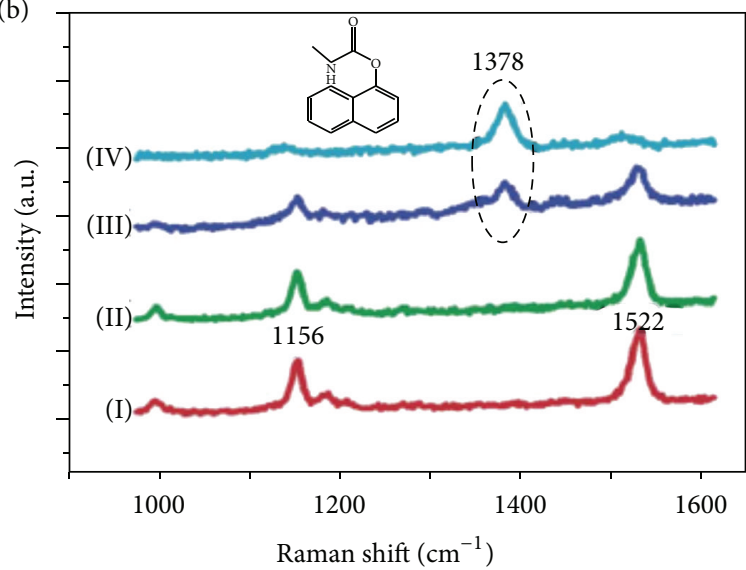

(c)

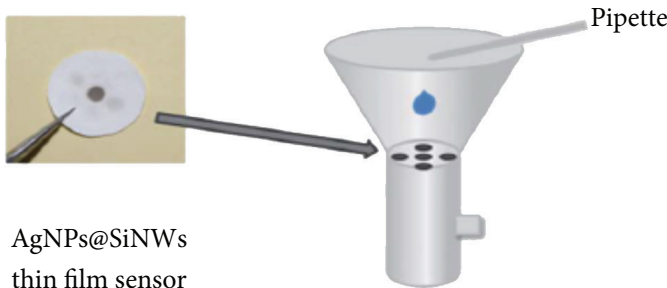

(d)

thin film sensor

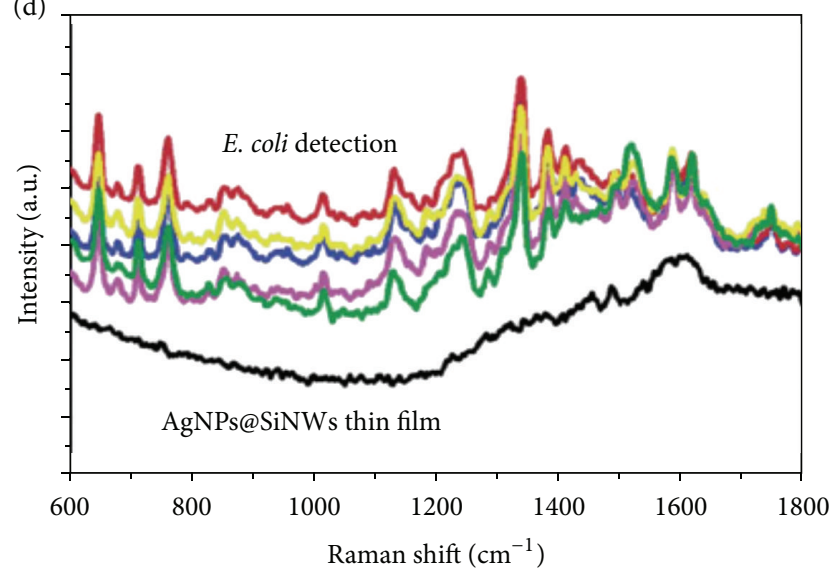

Figure 6: (a) Photograph of the detection of pesticide residues on a cucumber surface experiment (left) and the microscope image of a single AgNP@SiNW transferred to the rough cucumber surface (right). (b) Raman spectra recorded from the rough cucumber surface with $1 \mathrm{~s}$ acquisition time and 50x objective. Curve I, clean cucumber surface; curve II, carbaryl contaminated surface; curve III, SERS spectra of a carbaryl contaminated surface modified by a single AgNP@SiNW; curve IV, SERS spectra of pure carbaryl. (c) Photograph of SiNWs assembled on a commercially available filter film (with a pore size of $0.22 \mu \mathrm{m}$ ) and schematic of the E. coli detection. (d) Raman spectra recorded from a blank thin film and five different sites on the E. coli contaminated AgNP@SiNWs thin film with $10 \mathrm{~s}$ acquisition time and 50x objective. (Reprinted with permission from [74].)

was found that the modified SiNWs fluorescence sensor (MsiNWs) showed a rapid fluorescence response towards NO in a few seconds and was stable for days at room temperature. Besides showing high stability, rapid responses and high selectivity in the presence of reactive species, including $\mathrm{O}_{2}$, $\mathrm{NO}^{2-}, \mathrm{NO}^{3-}, \mathrm{H}_{2} \mathrm{O}_{2}, \mathrm{O}^{2-}, \mathrm{OH}, \mathrm{ClO}^{-}$, and $\mathrm{Fe}^{2+}$, were also achieved. Interestingly, the fluorescence images of single MSiNW before and after reacting with NO showed a fine spatial resolution when it was combined with microscopy techniques. In the presence of metal nanoparticle/SiNWs, nanomaterial showed a larger surface-enhanced fluorescence (SEF) for $\mathrm{Ln}^{3+}, \mathrm{Pr}^{3+}, \mathrm{Nd}^{3+}, \mathrm{Ho}^{3+}$, and $\mathrm{Er}^{3+}[79,80]$.

In the study of Zhuo et al. [81], the authors explained that the application of $\mathrm{Au} / \mathrm{SiNW}$ s nanomaterial enhanced the fluorescence intensity of $\mathrm{Ln}^{3+}$, which was about 169-fold, 67-fold, and 58-fold for $\mathrm{Nd}^{3+}, \mathrm{Ho}^{3+}$, and $\mathrm{Er}^{3+}$, respectively. Similar results were obtained when using different metal nanoparticles such as silver and copper modified SiNWs which were approximately twofold of SEF for $\mathrm{Ln}^{3+}$ ion compared with unsupported silver and copper nanoparticles [82]. This is because metal nanoparticle deposited firmly on the surface of SiNWs without aggregation, and the fields overlapped thus resulted in an optimum for enhancement of fluorescence's signals and caused a great SEF effect. Meanwhile, unsupported metal nanoparticle without SiNWs was easily aggregated due to the high surface energy of the small nanoparticle and the large particles were expected to meet stronger steric hindrances in the coupling.

3.3. Electrochemical Sensor Utilized SiNWs. The basic principle of electrochemical detection is based on redox reaction as a result of chemical reaction between immobilized biomolecule or chemical species on working electrode and target analyte which finally produces measurable electrical current [83]. The novel nonenzymatic method for detection of hydrogen peroxide $\left(\mathrm{H}_{2} \mathrm{O}_{2}\right)$ with high sensitivity and selectivity based on electrochemical method using nanostructure of $\mathrm{Ni}(\mathrm{OH})_{2}$-SiNWs was reported by Yan et al. [84]. In their study, the SiNW array was prepared using a chemical etching process followed by deposition of nickel film through electroless technique. The combination of $\mathrm{Ni}(\mathrm{OH})_{2}$ and $\mathrm{SiNWs}$ as working electrode exhibited high catalytic effect for $\left(\mathrm{H}_{2} \mathrm{O}_{2}\right)$ detection, which achieved sensitivity of $3.31 \mathrm{~mA} \cdot \mathrm{mM}^{-1} \cdot \mathrm{cm}^{-1}$ with detection limit of $3.2 \mu \mathrm{M}$ and high stability. Based on previous studies, there is a great interest in the application of SiNWs functionalized with metal nanoparticle due to enhancement of electron transfer of enzyme activity and electrical conductivity.

$\mathrm{Su}$ et al. [47] have fabricated SiNWs via oxide assisted growth technique and treated with $5 \% \mathrm{HF}$ to produce $\mathrm{H}$ terminated layer. This $\mathrm{H}$-terminated layer acts as a strong reducing agent which can reduce $1 \% \mathrm{HAuCl}_{4}$ to AuNPs on 


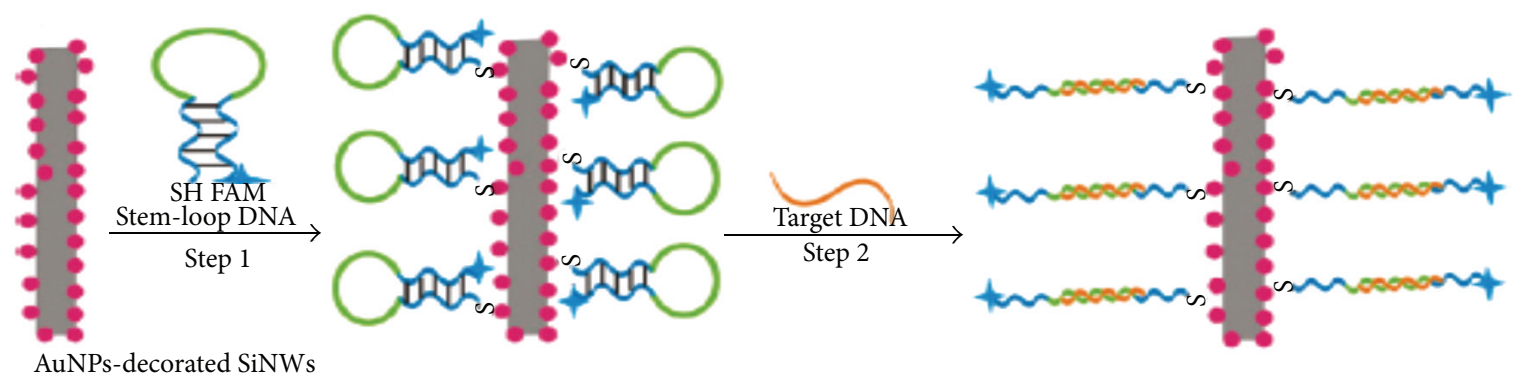

(a)

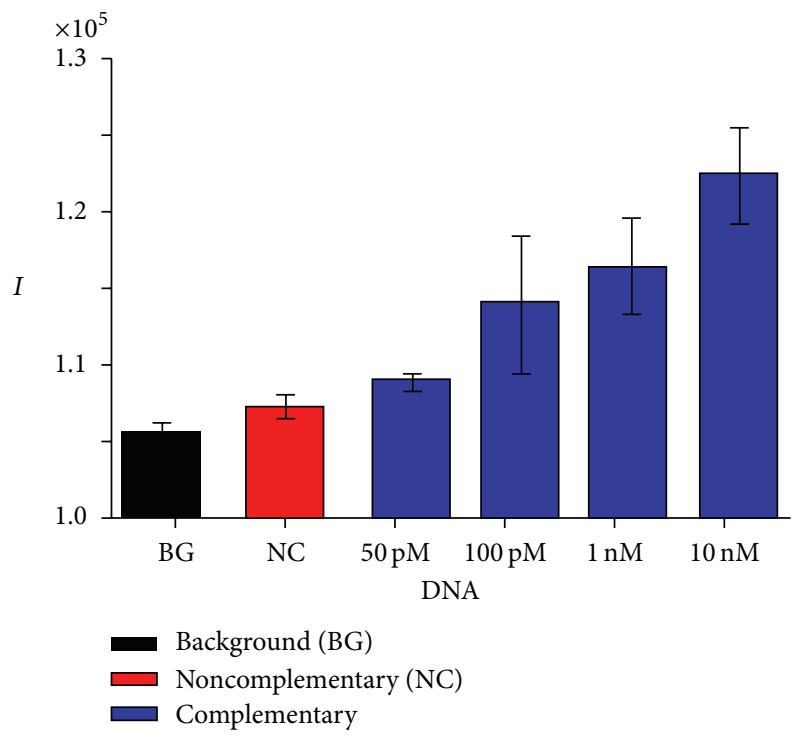

(b)

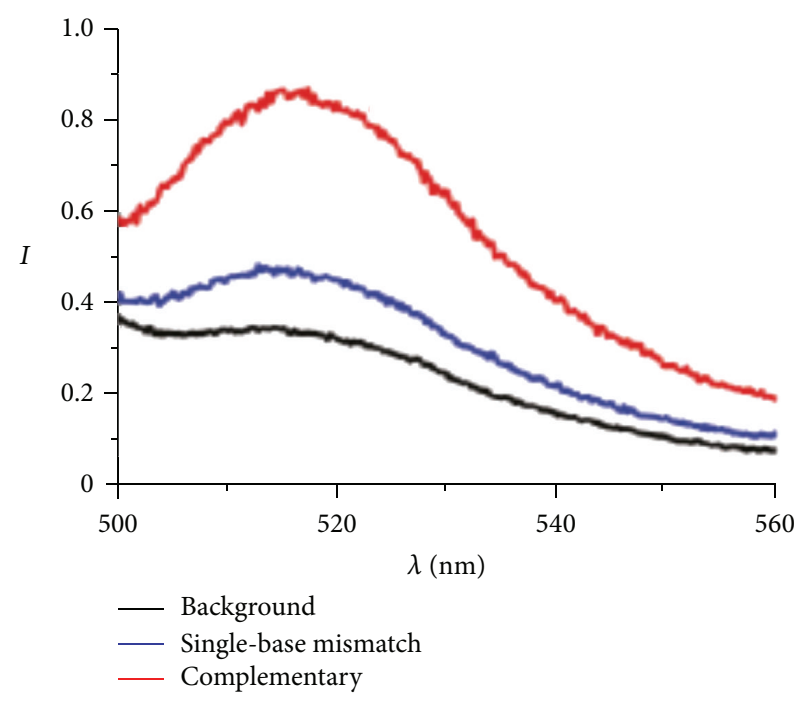

(c)

FIGURE 7: (a) Schematic preparation of silicon-based nano-MBs for DNA analysis. (b) Fluorescence intensity of different concentrations of complementary target DNA. Background and noncomplemetary sequence are presented as control. (c) Photoluminescence spectra of FAM-tagged probes in the absence and presence of $10 \mathrm{nM}$ complementary target DNA and single-based mismatched DNA. (Reprinted with permission from [75].)

the surface of SiNWs. The authors demonstrated that SiNWsAuNPs modified carbon electrode exhibits high sensitivity compared with the unmodified carbon electrode (Figure 9). It was clearly shown that SiNWs enable to increase the electrical conductivity of modified electrode and facilitate electron transfer of acetylcholinesterase (AChE) for organophosphate pesticide detection. The authors found that the SiNWs modified electrode showed rapid response in the detection of acetylcholine in the range of $1.0 \mu \mathrm{M}-1.0 \mathrm{mM}$ and was highly sensitive down to $8 \mathrm{ng} \mathrm{L}^{-1}$.

According to $\mathrm{Su}$ et al. [85], the electron transfer got greatly enhanced when the surfaces of SiNWs were coated with Au nanoparticles for detection of dopamine (DA), a neurotransmitter in brain. The author found that SiNWs electrode produced a weak peak current. Meanwhile, the modified AuNPs/SiNWs electrode showed a pair of welldefined quasireversible peaks at $0.23 \mathrm{~V}$ and $0.09 \mathrm{~V}$ for oxidation and reduction potentials, respectively (Figure 10). However, the application of SiNW arrays functionalized with $\mathrm{Au}$ nanoparticle enhanced the sensitivity of dopamine down to $40 \mathrm{nM}$, which was lower than Au/AuNP-modified electrode $(220 \mathrm{nM})$. The enrichment of dopamine on the surface of SiNWs was assisted with the negative charge on SiNWs/AuNPs electrode via electrostatic interaction. The authors also reported the detection of ascorbic acid by cyclic voltammetry (CV) method using the same AuNPs/SiNWs electrode with a detection limit of $500 \mathrm{nM}$. The success of SiNWs/AuNPs electrode is due to the advantages of SiNWs/AuNPs electrode in terms of increasing mass transport and enhancing electron transfer. Therefore SiNWs/AuNPs electrode can be one of the vast applicable electrodes for electrochemical detection in the future.

Moreover, SiNWs/AuNPs based biosensor for glutathione (GSH) was fabricated and showed a fast response to the GSH concentration in the range of $0.33-2.97 \mu \mathrm{M}$ [86]. There are also some studies using single SiNWs strands (height in $2 \mathrm{~mm}$ and diameter of $35 \mathrm{~mm}$ ) decorated with $\mathrm{Au}$ nanoparticles as working electrode for Bovine Serum Albumin (BSA) detection, which achieved detection as low as $0.2 \mu \mathrm{M}$ [87]. Kwon et al. [88] who fabricated the vertical SiNW arrays decorated with AuNPs using selfassembled monolayer (SAM) of APTES demonstrated detection of BSA protein in the range of $1.0-7.0 \mu \mathrm{M}$. Moreover, the nafion/Gox/SiNWs/AuNPs/GCE was fabricated by the 


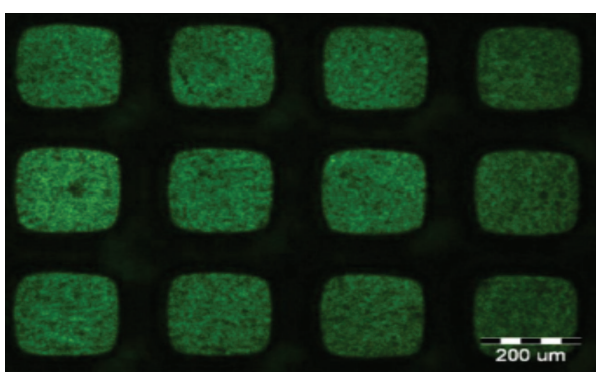

(a)

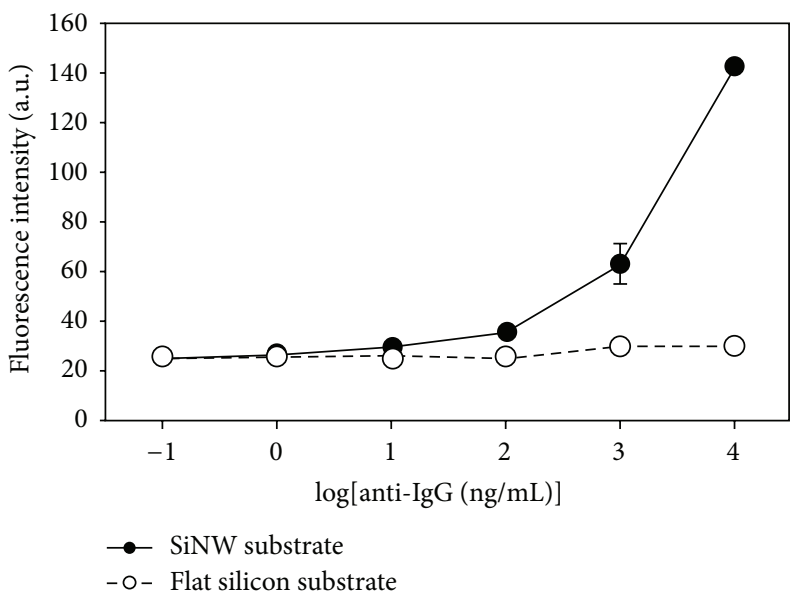

(c)

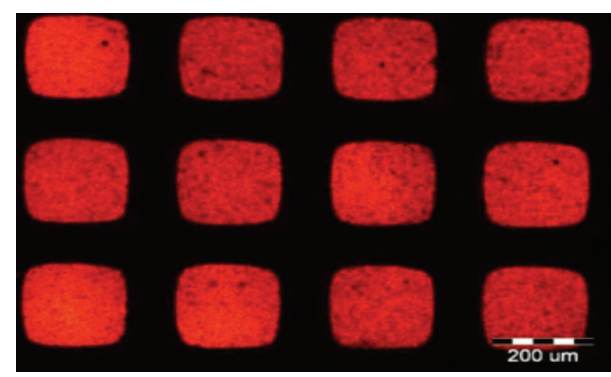

(b)

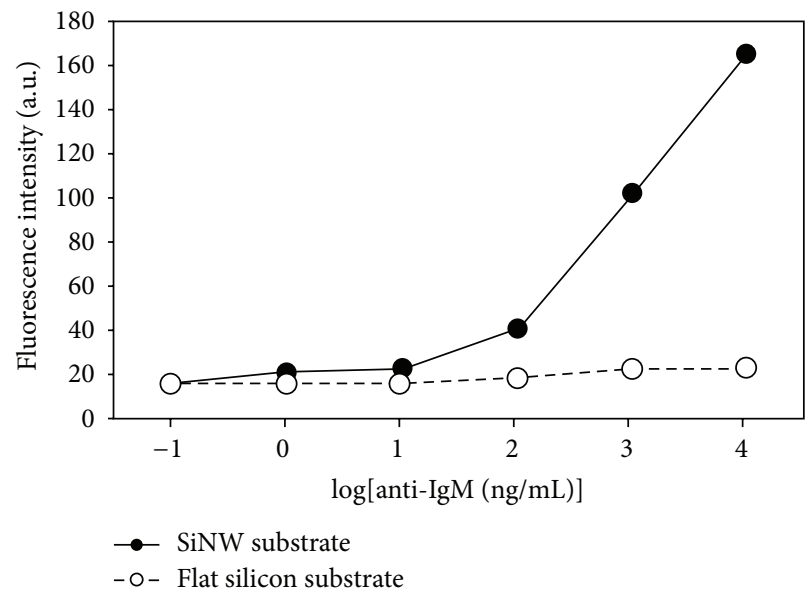

(d)

FIGURE 8: Immunoassays with micropatterned SiNWs. Fluorescent images obtained from reaction (a) between IgG and FITC-anti IgG and (b) between IgM and Cy3-anti IgM. Change in fluorescence intensity with concentration of (c) FITC-anti IgG and (d) Cy3-anti IgM. (Reprinted with permission from [78].)

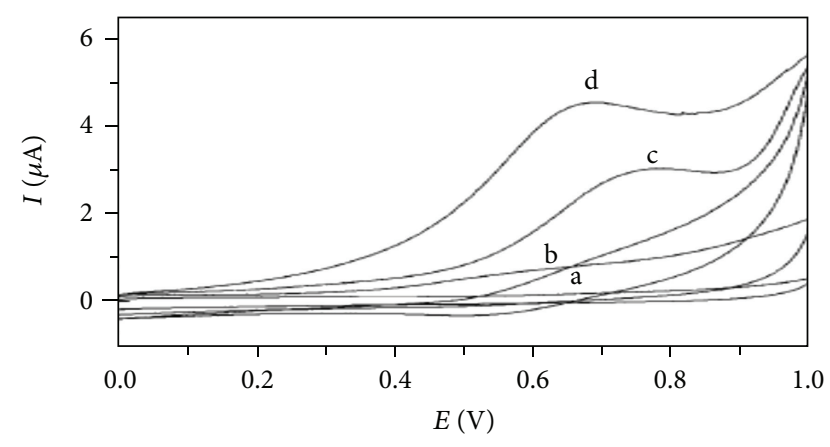

FIGURE 9: Cyclic voltammetry for a serial of electrodes (a) bare GCE (b) AChE modified GCE (c) Nafion/AChE/AuNPs modified GCE and (d) Nafion/AChE/AuNPs/SiNWs modified GCE in pH 7.4 PBS containing $1.0 \mathrm{mM}$ ATCl (scan rate: $50 \mathrm{mV} \mathrm{s}^{-1}$ ). (Reprinted with permission from [47].)

research group of $\mathrm{Su}$ et al. [89] to enhance biocatalytic activity of glucose oxidase (Gox) for high sensitivity glucose detection, which led to detection limit of $50 \mu \mathrm{M}$, enough to monitor blood-glucose levels typically ranging in 4.46.6 mM. Since the enzyme based biosensor exposed the loss of activity of enzyme, which is affected by temperature, $\mathrm{pH}$, humidity, and toxic chemicals [90], there was also an attempt of development of glucose sensor based Pd-Ni/SiNWs without immobilization with other mediators or enzymes [91]. The authors investigated the electrocatalytic behavior of Pd$\mathrm{Ni} / \mathrm{SiNW}$ s electrode via CV method in $0.1 \mathrm{M} \mathrm{KOH}$ containing $10 \mathrm{mM}$ glucose and found that two well oxidation peaks were observed at the potential of $-0.27 \mathrm{~V}$ and -0.07 due to glucose oxidation process. The developed $\mathrm{Pd}-\mathrm{Ni} / \mathrm{SiNWs}$ electrode was tested with different concentrations of glucose and achieved sensitivity of $190.7 \mu \mathrm{A} \cdot \mathrm{mM}^{-1}$ with detection limit of $2.88 \mu \mathrm{M}$.

3.4. Field-Effect Transistors (FET) Sensor Utilized SiNWs. SiNWs-FET sensor consists of three electrodes, which are source, drain, and gate electrode, and its work is based on conductive change of the carrier on the surface of SiNWs either accumulation or depletion charge. When negative charged molecules bind on n-type SiNW surface it results in accumulation of the negative carriers thus increasing the resistance reading and vice versa if using p-type SiNWs [92]. Gao et al. [93] have developed high performance of label free and direct time for DNA detection using SiNWs-FET sensor using top-down approach. In this work, they managed to improve the sensitivity of SiNWs-FET sensor by optimization of probe concentration, buffer ionic strength, and the gate voltage. SiNW surface was first modified by the amine group 


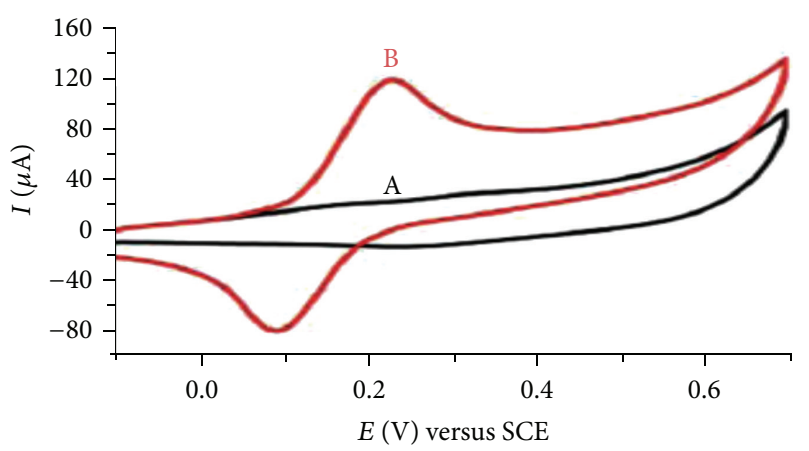

(a)

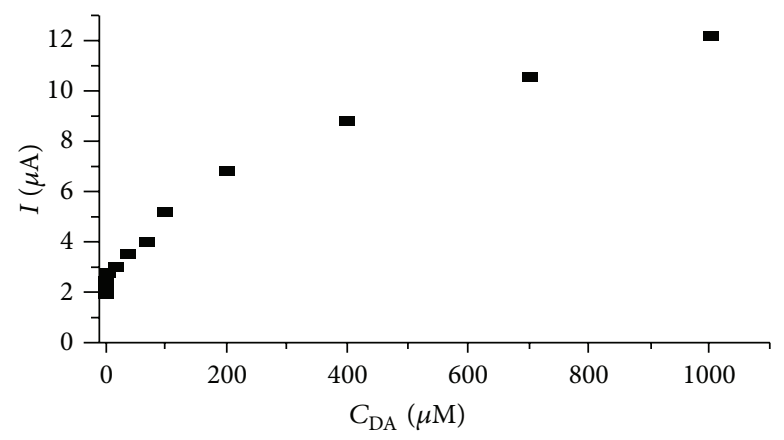

(c)

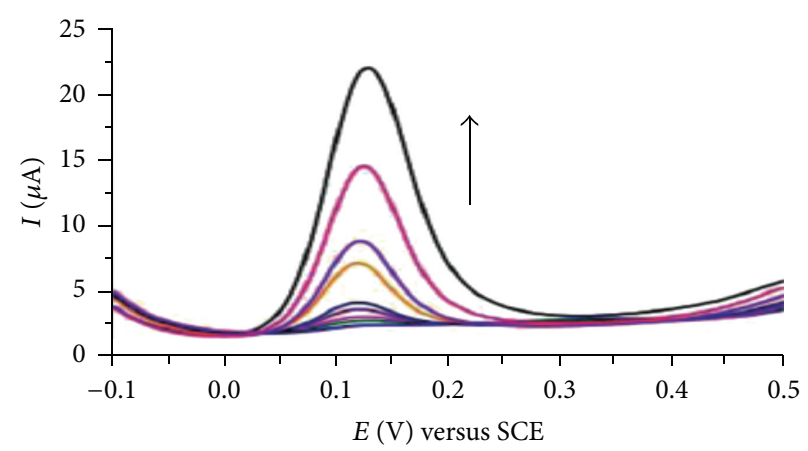

(b)

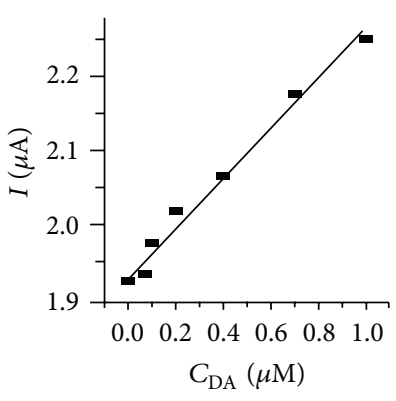

(d)

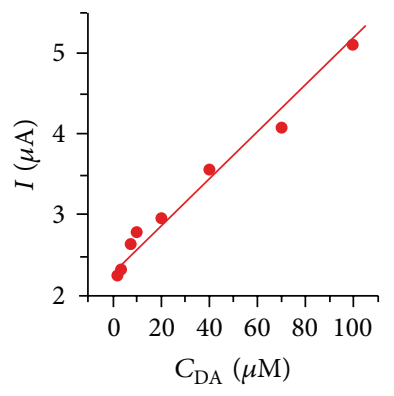

(e)

Figure 10: (a) Cyclic voltammograms of AuNPs/SiNWsAr electrode. (A) In the absence and (B) in the presence of $50 \mu \mathrm{M}$ DA in pH 7.0 PBS. Scan rate was $0.1 \mathrm{~V} \mathrm{~s}^{-1}$. (b) Differential pulse voltammograms at different concentrations of DA. ((d) and (e)) Linear relationship between the peak current and the concentration of DA. (Reprinted with permission from [85].)

of APTES and functionalized with carboxyl ( $\mathrm{COOH}-)$ group modified target DNA via $\mathrm{N}$-hydroxysuccinimide (NHS) and 1 ethyl 3-(3-dimethylaminopropyl)carbodiimide (EDC). Since DNA probe possesses a negative charge due to the phosphate group that binds on SiNW surfaces via SAM layer of amine group and carboxyl group as described before, leading to an increase of resistance and same observation obtained when hybridization occurred. The authors found that the optimized SiNWs-FET sensor presented detection limit of $0.1 \mathrm{fM}$ for DNA target (Figure 11). Moreover, the current change displayed around $40 \%$ when DNA probe hybridized with full complementary target DNA and only $20 \%$ and $5 \%$ upon the introduction of single and second base mismatched DNA.

Chen et al. [94] studied the utilization of electrically neutral ethylated DNA (E-DNA) and general DNA as a probe target on the performance of SiNWs-FET sensor. The authors found that E-DNA probe helps to enhance sensitivity of hybridization signal in terms of resistance change, which was $23.3 \%$ higher than general DNA. Surface plasma resonance (SPR) response also proved that the amount of complementary DNA hybridized with E-DNA is higher than general probe DNA. This can be explained such that E-DNA used in their work does not have an anionic backbone of the phosphate group. Therefore, there is less electrostatic repulsion between E-DNA and c-DNA than DNA and cDNA. Zhang et al. [95] also utilized neutral charge DNA analogue, peptide nucleic acid (PNA), as probe immobilization on the surface of SiNWs-FET sensor which was able to detect miRNA concentration as low as $1 \mathrm{fM}$. Furthermore, SiNWsFET sensor based PNA-miRNA demonstrated high sequence specific of full complementary, single base mismatched miRNA and noncomplemetary miRNA.

A novel detection method for DNA-protein interaction related to breast cancer, estrogen receptor alpha (ER $\alpha$ ) reported by Zhang et al. [96] using SiNWs-FET sensor. In their work, the amines group modified ER $\alpha$ (wild type, mutant, and noncomplementary) probe was functionalized on SiNW surface via vinyl terminated of self-assembly monolayer (SAM) process and showed high sequence specificity of $\mathrm{ER} \alpha$ detection, which produced $33 \%$ of conductance change upon the interaction of wild type of ERE and ER $\alpha$. The results showed a smaller conductance change of $8.4 \%$ for detection of ER $\alpha$ using mutant ERE and a negligible charge also observed for bonding to the scrambled DNA. The authors explored the detection of ER $\alpha$ in a crude extract from breast cancer cells and found the change of conductance around 23.4\% and 5.6\% when ER $\alpha$ bound to the wild-type ERE and negative ERE, respectively. They concluded that DNA protein functionalized SiNWs-FET sensor produced $10.3 \%$ of conductance with detection limits of $10 \mathrm{fM}$ for ER $\alpha$.

C-reactive protein (CRP) and prostate-specific antigen (PSA) were simultaneously detected based on antigenantibody interaction using SiNW array chip FET sensor [97]. The authors utilized sol-gel approach to immobilize antiCRP and anti-PSA on SiNW arrays instead of using chemical 


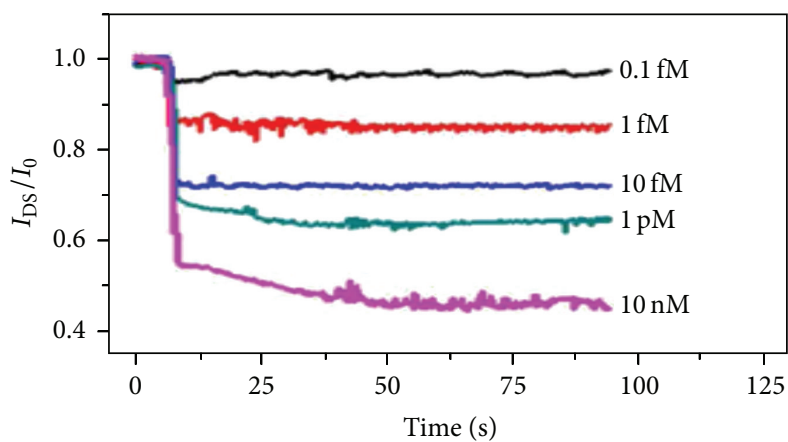

(a)

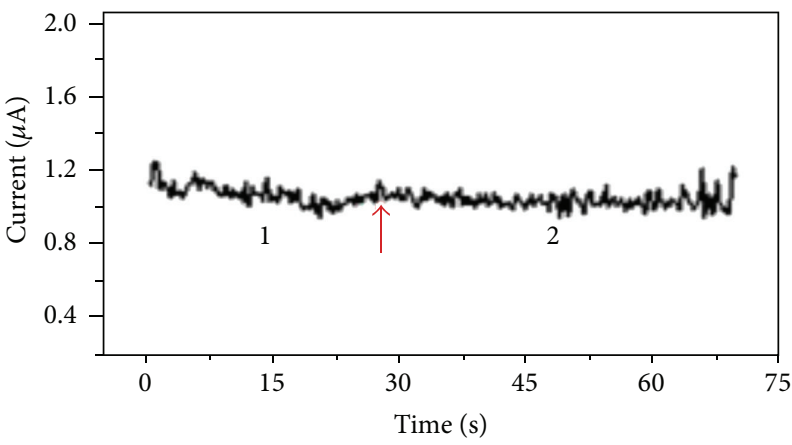

(c)

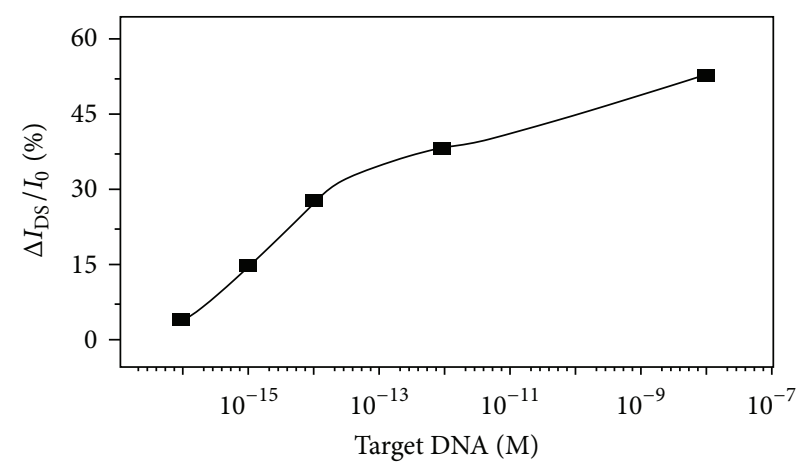

(b)

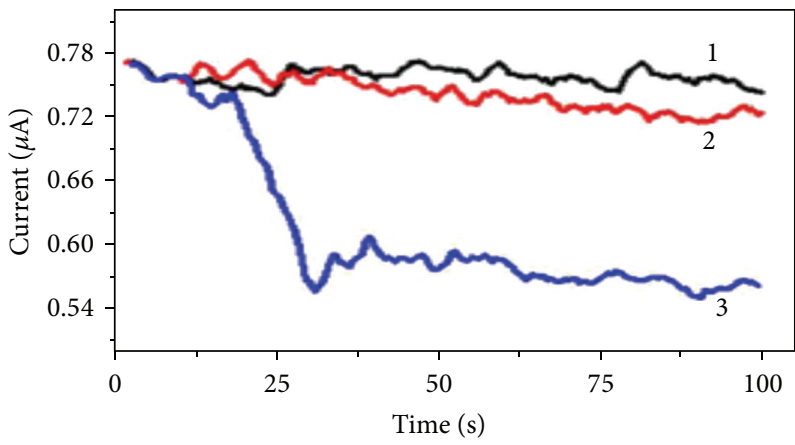

(d)

FIGURE 11: (a) Plots of normalized current change versus time with target DNA at a series of concentrations $(0.1 \mathrm{fM}, 1 \mathrm{fM}, 10 \mathrm{fM}, 1 \mathrm{pM}$, and $10 \mathrm{nM}$ ) for probe DNA modified SiNW device. Hybridization was demonstrated by $0.5 \mu \mathrm{M}$ probe DNA functionalized SiNW biosensor in $0.01 \times$ PBS. The length of all SiNWs was $6 \mu \mathrm{m}$. (b) Normalized current change as a function of the logarithm of target DNA concentration. (c) Plot of current versus time for unmodified SiNWs-FET, where region 1 stands for the presence of buffer solution and region 2 for the addition of $1 \mathrm{nM}$ of fully target DNA. The error marks the point when the solution was changed. (d) Hybridization specificity demonstrated by $10 \mathrm{nM}$ target DNAs. (Reprinted with permission from [93].)

modification to avoid loss of protein activity and maintain conformation of antibody. It was found that integration of sol-gel method exhibited high sensitivity with a low amount of serum for simultaneous detection of CRP and PSA in the range of $0.12-10 \mathrm{ng} / \mathrm{mL}$ and $0.18-8.81 \mathrm{ng} / \mathrm{mL}$, respectively.

Moreover, Zhang et al. [98] demonstrated for the first time the fabrication of SiNWs-FET sensor based carbohydrate-protein interaction where unmodified carbohydrate is immobilized via formation of an oxime bonding (reaction of amine group from APTES and BOCaminooxyacetic acid). Their finding on the new developed sensor exhibited high specificity of lectin EC detection through galactose-modified SiNW sensor which is capable of detecting as low as $100 \mathrm{fg} / \mathrm{m}$, four times higher than any other sensors reported previously (Figure 12).

The application of SiNWs-FET sensor for biomarker detection also demonstrated by $\mathrm{Wu}$ et al. [99] who managed to fabricate high sensitivity of interleukin- $1 \beta$ genes, indicator for breast, colon, lung, head, and neck cancers. To increase the sensitivity of SiNWs-FET device, the authors investigated the effect of oxygen $\left(\mathrm{O}_{2}\right)$ and nitrogen oxide $\left(\mathrm{N}_{2} \mathrm{O}\right)$ treatment on SiNW surface in order to enhance the capture DNA immobilization efficiency. They found out that one-minute $\mathrm{N}_{2} \mathrm{O}$ plasma treatment was the optimum time to capture DNA immobilization and at the same time maintain the electrical performance of SiNWs-FET. Under the optimal capture DNA functionalized SiNWs-FET via $\mathrm{N}_{2} \mathrm{O}$ treatment, 20 -mer fragment of IL- $1 \beta$ was hybridized with capture DNA showing the sensitivity and detection limit of $0.12 /$ decade and $252009 \mathrm{fM}$, respectively. The direct and real time detection of influenza virus $\left(\mathrm{H}_{3} \mathrm{~N}_{2}, \mathrm{H} 1 \mathrm{~N} 1\right.$, and 8 iso PGF 2 a biomarker) from exhaled breath condensate (EBC) based on antibody functionalized SiNWs-FET sensor was established by Shen et al. [100]. EBC samples were collected from human subjects with and without flu and diluted (100-fold) before being delivered to the virus antibody functionalized SiNWs-FET device, which resulted in detection as low as 29 viruses $/ \mu \mathrm{L}$. The authors made a conclusion that $90 \%$ of the EBC samples tested with negative or positive results by standard method of RT-qPCR showed similar patterns when applied with SiNWs-FET detection. They also introduced virus antibody modified magnetic beads to enhance the sensitivity in low level of virus in EBC before direct detection of SiNWsFET sensor. Svendsen et al. [101] demonstrated approximately $50 \%$ resistance change using virus antibody functionalized SiNWs-FET devices when applied on infected serum sample with the aleutian disease virus (ADV) from mink than healthy mink.

Besides the application of SiNWs-FET sensor in detecting molecule, heavy-metal detection based SiNWs-FET sensor 

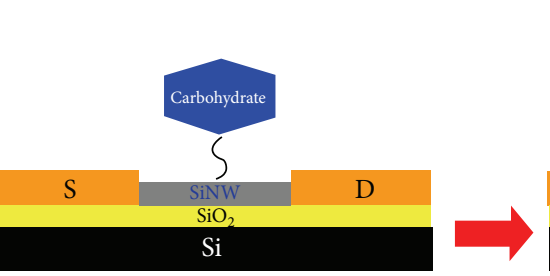

(a)

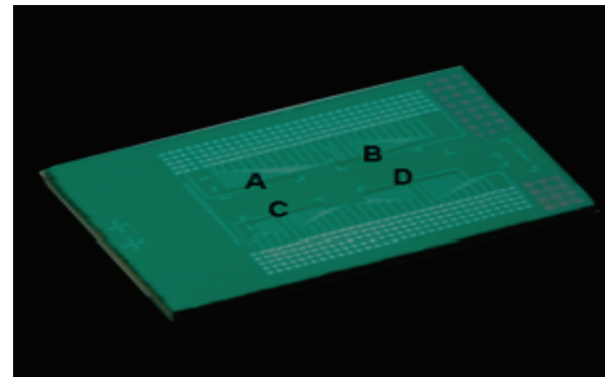

(b)

FIGURE 12: (a) Schematic diagram of the SiNW biosensor for free detection of carbohydrate-protein interaction. (b) Optical image of a SiNW sensor chip with four clusters. (Reprinted with permission from [98].)

has also received great attention recently. For example, Bi et al. [102] have designed ultrasensitive SiNWs-FET sensor for simultaneous detection of $\mathrm{Cu}^{2+}$ and $\mathrm{Pb}^{2+}$ in two different channels using oligopeptide modified SiNW arrays. They suggested that modified SiNWs with $\mathrm{Pb}^{2+}$ probe oligopeptide consisted of Cys-Asp-Arg-Val-Tyr-Ile-His-Pro-Phe-His-Leu and $\mathrm{Cu}^{2+}$ probe oligopeptide consisted of Gly-Gly-His were immobilized independently on SiNW surfaces and exhibited high selectivity also capability of achieving low detection limits for $\mathrm{Cu}^{2+}$ and $\mathrm{Pb}^{2+}$ as low as $1 \mathrm{nM}$ and $10 \mathrm{nM}$, respectively.

Detection of toxic heavy-metal cations such as $\mathrm{Cd}^{2+}$ and $\mathrm{Hg}^{2+}$ based on single-SiNWs-FET sensor has been fabricated by the group of Luo et al. [103]. SiNW surfaces was functionalized with mercaptopropyl silane (MPTES) as the chelating agent to bind $\mathrm{Cd}^{2+}$ and $\mathrm{Hg}^{2+}$ ions leading to the accumulation of positive charge of SiNW surface and resulting in the increase of current. This developed sensor is based on interaction between thiol groups and $\mathrm{Cd}^{2+}$ and $\mathrm{Hg}^{2+}$. The developed FET sensor based SiNW was enabled to detect $\mathrm{Cd}^{2+}$ and $\mathrm{Hg}^{2+}$ as low as $10^{-4}$ and $10^{-7} \mathrm{M}$, respectively.

Table 2 summarized the applications of SiNW in different techniques as described above.

\section{Conclusions and Perspective}

We noticed that the hybrid of SiNWs with metal nanoparticles such as gold nanoparticles (AuNPs) and silver nanoparticles (AgNPs) presents a new generation of sensing material electrodes with excellent catalytic activity and high conductivity that can greatly enhance the performance of sensors in terms of sensitivity and selectivity. We believe that the integration of SiNWs as sensing nanomaterials has great interesting in future for fabrication of of miniaturized sensor devices due to their unique properties. In our opinion, the electrochemical and electrical detection showed a great promise in realizing a miniaturized sensor based on SiNWs due to its advantages including high detection, portability, and simplicity of the procedure. However, a few challenges must be overcome. Firstly, the fabrication technique of SiNWs either bottom-up approach or top-down approach must be strongly developed to ensure the reliable electrochemical and electrical SiNW sensor. Highly controlled SiNW fabrication
TABLE 2: Application of SiNWs in sensor technologies.

\begin{tabular}{|c|c|c|}
\hline Technique & Application/detection & Reference \\
\hline \multirow{3}{*}{$\begin{array}{l}\text { Surface- } \\
\text { enhanced } \\
\text { Raman } \\
\text { scattering }\end{array}$} & $\begin{array}{l}\text { Amoxicillin, calcium } \\
\text { dipicolinate }\end{array}$ & {$[71]$} \\
\hline & $\begin{array}{c}\text { Protein, } \\
\text { immunoglobulin }\end{array}$ & {$[72]$} \\
\hline & $\begin{array}{l}\text { Rhodamine, crystal } \\
\text { violet, nicotine, calf } \\
\text { thymus DNA }\end{array}$ & {$[50]$} \\
\hline \multirow{6}{*}{$\begin{array}{l}\text { Fluorescence } \\
\text { sensor }\end{array}$} & $\begin{array}{c}\text { Multiplex DNA } \\
\text { detection }\end{array}$ & [73] \\
\hline & DNA hybridization & {$[77]$} \\
\hline & Protein immunosensor & {$[78]$} \\
\hline & $\mathrm{Cu}(\mathrm{II})$ detection & {$[79]$} \\
\hline & NO detection & {$[80]$} \\
\hline & Ln (III) detection & {$[81]$} \\
\hline \multirow{6}{*}{$\begin{array}{l}\text { Electrochemical } \\
\text { sensor }\end{array}$} & $\mathrm{H}_{2} \mathrm{O}_{2}$ detection & {$[84]$} \\
\hline & $\begin{array}{l}\text { Organophosphate } \\
\text { pesticide detection }\end{array}$ & {$[47]$} \\
\hline & Dopamine & {$[85]$} \\
\hline & Glutathione & {$[86]$} \\
\hline & BSA & {$[87,88]$} \\
\hline & Glucose & {$[89,91]$} \\
\hline \multirow{9}{*}{$\begin{array}{l}\text { Field effect } \\
\text { transistors }\end{array}$} & $\begin{array}{l}\text { DNA detection and } \\
\text { hybridization }\end{array}$ & {$[93,94]$} \\
\hline & miRNA determination & {$[95]$} \\
\hline & $\mathrm{ER} \alpha$ detection & {$[96]$} \\
\hline & CRP and PSA detection & [97] \\
\hline & Lectin EC detection & {$[98]$} \\
\hline & Interleukin-I $\beta$ genes & {$[99]$} \\
\hline & Influenza virus & {$[100]$} \\
\hline & Aleutian disease virus & {$[101]$} \\
\hline & $\mathrm{Cu}^{2+}, \mathrm{Pb}^{2+}, \mathrm{Cd}^{2+}, \mathrm{Hg}^{2+}$ & {$[102,103]$} \\
\hline
\end{tabular}

in terms of surface, diameter, length, alignment, and so forth should become the main barrier in the bottom-up technique and therefore the parameter manipulation of SiNW synthesis has to be established as the initial step for development of 
reproducible sensor based SiNWs. Secondly, since most of the bottom-up techniques produce SiNW suspension followed by dispersing method for the SiNW integration in sensor system, it is quite hard to control the distribution (align) and identical desired direction. Therefore, there is a need for the development technique of casting or alignment of SiNWs in order to control their distribution and quantity. In contrast, top-down approach can provide high control of SiNW synthesis and alignment; however, the high cost of fabrication of SiNW sensors became the main barrier to develop a low cost portable sensor involving advanced lithography tools. For the top-down approach, there are great efforts to find another low costing and effective method for fabrication of reliable sensors. In summary, SiNW is the promising nanomaterial sensing in the future.

\section{References}

[1] G. Wang, A. H. Dewilde, J. Zhang et al., "A living cell quartz crystal microbalance biosensor for continuous monitoring of cytotoxic responses of macrophages to single-walled carbon nanotubes," Particle and Fibre Toxicology, vol. 8, article 4, 2011.

[2] Q. Zhang, J. Ding, L. Kou, and Q. Wei, "Potentiometric flow biosensor based on ammonia-oxidizing bacteria for the detection of toxicity in water," Sensors, vol. 13, pp. 6936-6945, 2013.

[3] X. Xu and Y. Ying, "Microbial biosensors for environmental monitoring and food analysis," Food Reviews International, vol. 27, no. 3, pp. 300-329, 2011.

[4] J. Lukasiak, C. A. Georgiou, K. Olsen, and D. G. Georgakopoulos, "Development of an L-rhamnose bioluminescent microbial biosensor for analysis of food ingredients," European Food Research Technology, vol. 235, pp. 573-579, 2012.

[5] J. Yuan, R. Duan, H. Yang, X. Luo, and M. Xi, "Detection of serum human epididymis secretory protein in patients with ovarian cancer using a label-free biosensor based on localized surface plasmon resonance," International Journal of Nanomedicine, vol. 7, pp. 2921-2928, 2012.

[6] Y. Cao, J. Yu, B. Bo, Y. Shu, and G. Li, "A simple and general approach to assay protease activity with electrochemical technique," Biosensors and Bioelectronics, vol. 45, pp. 1-5, 2013.

[7] J. Y. Wu, C. L. Tseng, Y. K. Wang, Y. Yu, K. L. Ou, and C. C. $\mathrm{Wu}$, "Detecting interleukin-1b genes using a $\mathrm{N}_{2} \mathrm{O}$ plasma modified silicon nanowire biosensor," Journal of Experimental and Clinical Medicine, vol. 5, pp. 12-16, 2013.

[8] G. L. Turdean, "Design and development of biosensors for the detection of heavy metal toxicity," International Journal of Electrochemistry, vol. 2011, Article ID 343125, 15 pages, 2011.

[9] Y. Huang, L. Wieck, and S. Tao, "Development and evaluation of optical fiber $\mathrm{NH}_{3}$ sensors for application in air quality monitoring," Atmospheric Environment, vol. 66, pp. 1-7, 2013.

[10] M. Minunni, S. Tombelli, M. Mascini, A. Bilia, M. C. Bergonzi, and F. F. Vincieri, "An optical DNA-based biosensor for the analysis of bioactive constituents with application in drug and herbal drug screening," Talanta, vol. 65, no. 2, pp. 578-585, 2005.

[11] L. G. Zamfir, L. Rotariu, and C. Bala, "Acetylcholinesterase biosensor for carbamate drugs based on tetrathiafulvalenetetracyanoquinodimethane/ionic liquid conductive gels," Biosensors and Bioelectronics, vol. 46, pp. 61-67, 2013.
[12] A. Kaur, M. Verma, and S. Kamaljit, "Biosensor and its clinical application," International Journal of Advanced Research, vol. 1, pp. 108-118, 2013.

[13] A. Zhang, S. You, C. Soci, Y. Liu, D. Wang, and Y.-H. Lo, "Silicon nanowire detectors showing phototransistive gain," Applied Physics Letters, vol. 93, no. 12, Article ID 121110, 2008.

[14] F. Lucarelli, S. Tombelli, M. Minunni, G. Marrazza, and M. Mascini, "Electrochemical and piezoelectric DNA biosensors for hybridisation detection," Analytica Chimica Acta, vol. 609, no. 2, pp. 139-159, 2008.

[15] Y. Lei, W. Chen, and A. Mulchandani, "Microbial biosensors," Analytica Chimica Acta, vol. 568, no. 1-2, pp. 200-210, 2006.

[16] S. Rodriguez-Mozaz, M.-P. Marco, M. J. Lopez De Alda, and D. Barceló, "Biosensors for environmental applications: future development trends," Pure and Applied Chemistry, vol. 76, no. 4, pp. 723-752, 2004.

[17] E. B. Setterington and E. C. Alocilja, "Electrochemical biosensor for rapid and sensitive detection of magnetically extracted bacterial pathogens," Biosensors, vol. 2, pp. 15-31, 2012.

[18] K. Chen, Z. L. Zhang, Y. M. Liang, and W. Liu, "A graphenebased electrochemical sensor for rapid determination of phenols in water," Sensors, vol. 13, pp. 6204-6216, 2013.

[19] M. B. Lerner, J. Daileya, D. Brisson, and A. T. Johnson, "Detecting Lyme disease using antibody-functionalized single-walled carbon nanotube transistors," Biosensors and Bioelectronics, vol. 45, pp. 163-167, 2013.

[20] X. Xu, X. Liu, Y. Li, and Y. Ying, "A simple and rapid optical biosensor for detection of aflatoxin B1 based on competitive dispersion of gold nanorods," Biosensors and Bioelectronics, vol. 47, pp. 361-367, 2013.

[21] L. Su, L. Zou, C. C. Fong et al., "Detection of cancer biomarkers by piezoelectric biosensor using PZT ceramic resonator as the transducer," Biosensors and Bioelectronics, vol. 46, pp. 155-161, 2013.

[22] Y. Zheng, X. Liu, Y. Ma, Y. Xu, and F. Xu, "Research and development of a new versatile thermal biosensor," Sensors, vol. 9, pp. 1033-1053, 2009.

[23] X. Zhang, Q. Guo, and D. Cui, "Recent advances in nanotechnology applied to biosensors," International Journal of Advanced Research, vol. 1, pp. 108-118, 2009.

[24] Y. Umasankar and S.-M. Chen, "A review on the electrochemical sensors and biosensors composed of nanowires as sensing material," Sensors, vol. 8, no. 1, pp. 290-313, 2008.

[25] G. Tian, K. Pan, Y. Chen et al., "Vertically aligned anatase $\mathrm{TIO}_{2}$ nanowire bundle arrays: use as Pt support for counter electrodes in dye-sensitized solar cells," Journal of Power Sources, vol. 238, pp. 350-355, 2013.

[26] F. Shahdost-fard, A. Salimi, E. Sharifi, and A. Korani, "Fabrication of a highly sensitive adenosine aptasensor based on covalent attachment of aptamer onto chitosan-carbon nanotubesionic liquid nanocomposite," Biosensors and Bioelectronics, vol. 48, pp. 100-107, 2013.

[27] L. Qian, J. Mao, X. Tian, H. Yuan, and D. Xiao, "In situ synthesis of $\mathrm{CuS}$ nanotubes on $\mathrm{Cu}$ electrode for sensitive nonenzymatic glucose sensor," Sensors and Actuators B, vol. 176, pp. 952-959, 2013.

[28] Y. Ding, Y. Liu, J. Parisi, L. Zhang, and Y. Lei, "A novel NiO$\mathrm{Au}$ hybrid nanobelts based sensor for sensitive and selective glucose detection," Biosensors and Bioelectronics, vol. 28, no. 1, pp. 393-398, 2011. 
[29] Y. Sun, S. H. Yang, L. P. Lv et al., "A composite film of reduced graphene oxide modified vanadium oxide nanoribbons as a free standing cathode material for rechargeable lithium batteries," Journal of Power Sources, vol. 241, pp. 168-172, 2013.

[30] H. Lee, J. Hong, S. Lee, S. D. Kim, Y. W. Kim, and T. Lee, "Selectively grown vertical silicon nanowire $p-n^{+}$photodiodes via aqueous electroless etching," Applied Surface Science, vol. 274, pp. 79-84, 2013.

[31] A. Gao, N. Lu, P. Dai et al., "Silicon-nanowire-based CMOScompatible field-effect transistor nanosensors for ultrasensitive electrical detection of nucleic acids," Nano Letters, vol. 11, no. 9, pp. 3974-3978, 2011.

[32] J. Y. Oh, H. Y. Jang, W. J. Cho, and M. S. Islam, "Highly sensitive electrolyte-insulator semiconductor $\mathrm{pH}$ sensors enabled by silicon nanowires with $\mathrm{Al}_{2} \mathrm{O}_{3} / \mathrm{SiO}_{2}$ sensing membrane," Sensors and Actuators B, vol. 171, pp. 238-243, 2012.

[33] J. Bae, H. Kim, and X. M. Zhang, "Si nanowire metal-insulatorsemiconductor photodetectors as efficient light harvesters," Nanotechnology, Article ID 095502, p. 21, 2010.

[34] P. K. Kim, S. J. Cho, J. Sung, H. S. Oh, and G. Lim, "Biomolecules detection sensor using silicon nanowire," in The 2nd International Conference on Smart Materials and Nanotechnology in Engineering, vol. 7493 of Proceedings of SPIE, SPIE, Weihai, China, 2009.

[35] J. H. Choi, H. Kim, H. S. Kim et al., "MMP-2 detective silicon nanowire biosensor using enzymatic cleavage reaction," Journal of Biomedical Nanotechnology, vol. 9, pp. 732-745, 2013.

[36] A. A. Talin, L. L. Hunter, F. Ĺonard, and B. Rokad, "Large area, dense silicon nanowire array chemical sensors," Applied Physics Letters, vol. 89, no. 15, Article ID 153102, 2006.

[37] K.-I. Chen, B.-R. Li, and Y.-T. Chen, "Silicon nanowire fieldeffect transistor-based biosensors for biomedical diagnosis and cellular recording investigation," Nano Today, vol. 6, no. 2, pp. 131-154, 2011.

[38] O. A. Sadik, S. K. Mwilu, and A. Aluoch, "Smart electrochemical biosensors: from advanced materials to ultrasensitive devices," Electrochimica Acta, vol. 55, no. 14, pp. 4287-4295, 2010.

[39] R. S. Wagner and W. C. Ellis, "Vapor-liquid-solid mechanism of single crystal growth," Applied Physics Letters, vol. 4, no. 5, pp. 89-90, 1964.

[40] H. Suzuki, H. Araki, M. Tosa, and T. Noda, "Formation of silicon nanowires by CVD using gold catalysts at low temperatures," Materials Transactions, vol. 48, no. 8, pp. 2202-2206, 2007.

[41] T. W. Ho and F. C. Nan Hong, "A novel method to grow vertically aligned silicon nanowires on $\mathrm{Si}$ (111) and their optical absorption," Journal of Nanomaterials, vol. 2012, Article ID 274618, 9 pages, 2012.

[42] I. P. Jamal, K. C. Su, W. Kee Chan, M. Othman, S. Abdul Rahman, and Z. Aspanut, "Formation of silicon/carbon coreshell nanowires using carbon nitride nanorods template and gold catalyst," Journal of Nanomaterials, vol. 2013, Article ID 784150, 7 pages, 2013.

[43] Y. F. Zhang, Y. H. Tang, N. Wang et al., "Silicon nanowires prepared by laser ablation at high temperature," Applied Physics Letters, vol. 72, no. 15, pp. 1835-1837, 1998.

[44] V. Schmidt, J. V. Wittemann, S. Senz, and U. Gósele, "Silicon nanowires: a review on aspects of their growth and their electrical properties," Advanced Materials, vol. 21, no. 25-26, pp. 2681-2702, 2009.
[45] P. R. Bandaru and P. Pichanusakorn, "An outline of the synthesis and properties of silicon nanowires," Semiconductor Science and Technology, vol. 25, no. 2, Article ID 024003, 2010.

[46] L. Yang, H. Lin, T. Wang, S. Ye, and M. Shao, "Telluriummodified silicon nanowires with a large negative temperature coefficient of resistance," Applied Physical Letters, Article ID 133111, p. 101, 2012.

[47] S. Su, Y. He, M. Zhang et al., "High-sensitivity pesticide detection via silicon nanowires-supported acetylcholinesterasebased electrochemical sensors," Applied Physics Letters, vol. 93, no. 2, Article ID 023113, 2008.

[48] S. D. Hutagalung, K. A. Yaacob, and A. F. A. Aziz, "Oxideassisted growth of silicon nanowires by carbothermal evaporation," Applied Surface Science, vol. 254, no. 2, pp. 633-637, 2007.

[49] N. Wang, Y. H. Tang, Y. F. Zhang, C. S. Lee, I. Bello, and S. T. Lee, "Si nanowires grown from silicon oxide," Chemical Physics Letters, vol. 299, no. 2, pp. 237-242, 1999.

[50] M.-W. Shao, M.-L. Zhang, N.-B. Wong et al., "Ag-modified silicon nanowires substrate for ultrasensitive surface-enhanced raman spectroscopy," Applied Physics Letters, vol. 93, no. 23, Article ID 233118, 2008.

[51] R.-Q. Zhang, Y. Lifshitz, and S.-T. Lee, "Oxide-assisted growth of semiconducting nanowires," Advanced Materials, vol. 15, no. 7-8, pp. 635-640, 2003.

[52] W. Chen, H. Yao, C. H. Tzang, J. Zhu, M. Yang, and S.-T. Lee, "Silicon nanowires for high-sensitivity glucose detection," Applied Physics Letters, vol. 88, no. 21, Article ID 213104, 2006.

[53] Z. Huang, N. Geyer, P. Werner, J. De Boor, and U. Gösele, "Metal-assisted chemical etching of silicon: a review," Advanced Materials, vol. 23, no. 2, pp. 285-308, 2011.

[54] F. Bai, M. Li, D. Song, H. Yu, B. Jiang, and Y. Li, "Onestep synthesis of lightly doped porous silicon nanowires in $\mathrm{HF} / \mathrm{AgNO}_{3} / \mathrm{H}_{2} \mathrm{O}_{2}$ solution at room temperature," Journal of Solid State Chemistry, vol. 196, pp. 596-600, 2012.

[55] K. Peng, Y. Wu, H. Fang, X. Zhong, Y. Xu, and J. Zhu, "Uniform, axial-orientation alignment of one-dimensional single-crystal silicon nanostructure arrays," Angewandte Chemie, vol. 44, no. 18, pp. 2737-2742, 2005.

[56] K. W. Kolasinski, "Silicon nanostructures from electroless electrochemical etching," Current Opinion in Solid State and Materials Science, vol. 9, no. 1-2, pp. 73-83, 2005.

[57] N. Brahiti, S.-A. Bouanik, and T. Hadjersi, "Metal-assisted electroless etching of silicon in aqueous NH4HF2 solution," Applied Surface Science, vol. 258, no. 15, pp. 5628-5637, 2012.

[58] N. Megouda, R. Douani, T. Hadjersi, and R. Boukherroub, "Formation of aligned silicon nanowire on silicon by electroless etching in HF solution," Journal of Luminescence, vol. 129, no. 12, pp. 1750-1753, 2009.

[59] S.-C. Shiu, S.-B. Lin, S.-C. Hung, and C.-F. Lin, "Influence of pre-surface treatment on the morphology of silicon nanowires fabricated by metal-assisted etching," Applied Surface Science, vol. 257, no. 6, pp. 1829-1834, 2011.

[60] M.-L. Zhang, K.-Q. Peng, X. Fan et al., "Preparation of largearea uniform silicon nanowires arrays through metal-assisted chemical etching," Journal of Physical Chemistry C, vol. 112, no. 12, pp. 4444-4450, 2008.

[61] I. Park, Z. Li, A. P. Pisano, and R. S. Williams, “Top-down fabricated silicon nanowire sensors for real-time chemical detection," Nanotechnology, vol. 21, no. 1, Article ID 015501, 2010.

[62] X. T. Vu, R. GhoshMoulick, J. F. Eschermann, R. Stockmann, A. Offenhäusser, and S. Ingebrandt, "Fabrication and application 
of silicon nanowire transistor arrays for biomolecular detection," Sensors and Actuators B, vol. 144, no. 2, pp. 354-360, 2010.

[63] V. B. Pham, X. Thanh, T. Pham et al., "Detection of DNA of genetically modified maize by a silicon nanowire field-effect transistor," Nanoscience and Nanotechnology, vol. 2, Article ID 025010, 2011.

[64] A. Kulkarni, Y. Xu, C. Ahn et al., "The label free DNA sensor using a silicon nanowires array," Journal of Biotechnology, vol. 160, pp. 91-96, 2012.

[65] H. D. Tong, S. Chen, W. G. Van Der Wiel, E. T. Carlen, and A. D. Van Berg, "Novel top-down wafer-scale fabrication of single crystal silicon nanowires," Nano Letters, vol. 9, no. 3, pp. 10151022, 2009.

[66] S. Chen, J. G. Bomer, W. G. Van der Wiel, E. T. Carlen, and A. Van Den Berg, "Top-down fabrication of sub-30 nm monocrystalline silicon nanowires using conventional microfabrication," ACS Nano, vol. 3, no. 11, pp. 3485-3492, 2009.

[67] L. Gangloff, E. Minoux, K. B. K. Teo et al., "Self-aligned, gated arrays of individual nanotube and nanowire emitters," Nano Letters, vol. 4, no. 9, pp. 1575-1579, 2004.

[68] R. He, D. Gao, R. Fan et al., "Si nanowire bridges in microtrenches: integration of growth into device fabrication," Advanced Materials, vol. 17, no. 17, pp. 2098-2102, 2005.

[69] K. Haraguchi, K. Hiruma, T. Katsuyama, K. Tominaga, M. Shirai, and T. Shimada, "Self-organized fabrication of planar GaAs nanowhisker arrays," Applied Physics Letters, vol. 69, no. 3, pp. 386-387, 1996.

[70] M. S. Islam and W. C. Ellis, "Heteroepitaxial ultrafine wire-like growth of InAs on GaAs substrates," Applied Physics Letters, vol. 58, no. 10, pp. 1080-1082, 1991.

[71] B. Zhang, H. Wang, L. Lu, K. Ai, G. Zhang, and X. Cheng, "Large-area silver-coated silicon nanowire arrays for molecular sensing using surface-enhanced raman spectroscopy," Advanced Functional Materials, vol. 18, no. 16, pp. 2348-2355, 2008.

[72] M.-L. Zhang, C.-Q. Yi, X. Fan et al., "A surface-enhanced Raman spectroscopy substrate for highly sensitive label-free immunoassay," Applied Physics Letters, vol. 92, Article ID 043116, 2008.

[73] Z. Y. Jiang, X. X. Jiang, S. Su, X. P. Wei, S. T. Lee, and Y. He, "Silicon-based reproducible and active surface-enhanced Raman scattering substrate for sensitive, specific and multiplex DNA detection," Applied Physics Letters, vol. 100, Article ID 203104, 2012.

[74] X. Han, H. Wang, X. Ou, and X. Zhang, "Highly sensitive, reproducible, and stable SERS sensors based on well controlled silver nanoparticle-decorated silicon nanowire building blocks," Journal of Materials Chemistry, vol. 22, pp. 14127-14132, 2012.

[75] S. Su, X. Wei, Y. Zhong et al., "Silicon nanowire-based molecular beacons for high-sensitivity and sequence-specific DNA multiplexed analysis," ACS Nano, vol. 6, no. 3, pp. 2582-2590, 2012.

[76] P. Serre, C. Ternon, V. Stambouli et al., "Fabrication of silicon nanowire networks for biological sensing," Sensors and Actuators B, vol. 182, pp. 390-395, 2013.

[77] D. J. Maxwell, J. R. Taylor, and S. Nie, "Self-assembled nanoparticle probes for recognition and detection of biomolecules," Journal of the American Chemical Society, vol. 124, no. 32, pp. 9606-9612, 2002.

[78] S. W. Han, S. Lee, J. Hong, E. Jang, T. Lee, and W. G. Koh, "Multiscale substrated based on hydrogel-incorporated silicon nanowires for protein patterning and microarray-based immunoassays," Biosensors and Bioelectronics, vol. 45, pp. 129135, 2013.

[79] L. Mu, W. Shi, J. C. Chang, and S. T. Lee, "Silicon nanowiresbased florescence sensor for Cu (II)," Nanoletters, vol. 8, pp. 104109, 2007.

[80] R. Miao, L. Mu, H. Zhang et al., "Modified silicon nanowires: a fluorescent nitric oxide biosensor with enhanced selectivity and stability," Journal of Materials Chemistry, vol. 22, no. 8, pp. 3348-3353, 2012.

[81] S. Zhuo, M. Shao, H. Xu, T. Chen, D. D. D. Ma, and S. T. Lee, "Aumodified silicon nanowires for surface-enhanced fluorescence of $\mathrm{Ln}^{3+}$ (Ln 5 Pr, Nd, Ho, and Er)," Journal Material Science, vol. 24, pp. 324-330, 2013.

[82] S.-J. Zhuo, M.-W. Shao, L. Cheng, R.-H. Que, D. D. D. Ma, and S.-T. Lee, "Silver/silicon nanostructure for surface-enhanced fluorescence of $\mathrm{Ln}^{3+}(\mathrm{Ln}=\mathrm{Nd}$, Ho, and Er)," Journal of Applied Physics, vol. 108, no. 3, Article ID 034305, 2010.

[83] R. Monošík, M. Stred'anský, and E. Šturdík, "Biosensorsclassification, characterization and new trends," Acta Chimica Slovaca, vol. 5, pp. 109-120, 2012.

[84] Q. Yan, Z. Wang, J. Zhang et al., "Nickel hydroxide modified silicon nanowires electrode for hydrogen peroxide sensor applications," Electrochimica Acta, vol. 61, pp. 148-153, 2012.

[85] S. Su, X. Wei, Y. Guo et al., "A silicon nanowire-based electrochemical sensor with high sensitivity and electrocatalytic activity," Material Views, vol. 30, pp. 326-331, 2013.

[86] K. Yang, H. Wang, K. Zou, and X. Zhang, "Gold nanoparticle modified silicon nanowires as biosensors," Nanotechnology, vol. 17, no. 11, pp. S276-S279, 2006.

[87] M.-W. Shao, H. Yao, M.-L. Zhang, N.-B. Wong, Y.-Y. Shan, and S.-T. Lee, "Fabrication and application of long strands of silicon nanowires as sensors for bovine serum albumin detection," Applied Physics Letters, vol. 87, no. 18, Article ID 183106, 2005.

[88] D. H. Kwon, H. H. An, H.-S. Kim et al., "Electrochemical albumin sensing based on silicon nanowires modified by gold nanoparticles," Applied Surface Science, vol. 257, no. 10, pp. 4650-4654, 2011.

[89] S. Su, Y. He, S. Song et al., "A silicon nanowire-based electrochemical glucose biosensor with high electrocatalytic activity and sensitivity," Nanoscale, vol. 2, no. 9, pp. 1704-1707, 2010.

[90] Y. Shimizu and K. Morita, "Microhole array electrode as a glucose sensor," Analytical Chemistry, vol. 62, no. 14, pp. 14981501, 1990.

[91] S. Hui, J. Zhang, X. Chen et al., "Study of an amperometric glucose sensor based on Pd-Ni/SiNW electrode," Sensors and Actuators B, vol. 155, no. 2, pp. 592-597, 2011.

[92] G. J. Zhang and Y. Ning, "Silicon nanowire biosensor and its application in disease diagnostics," Analytica Chimica Acta, vol. 749, pp. 1-15, 2012.

[93] A. Gao, N. Lu, Y. Wang, P. Dai, X. Gao, and Y. Wang, "Enhanced sensing of nucleic acids with silicon nanowires field effect transistor biosensors," Nano Letters, vol. 12, pp. 5262-5268, 2012.

[94] W. Y. Chen, H. C. Chen, Y. S. Yang, C. J. Huang, H. W. H. C. Chan, and W. P. Hu, "Improved DNA detection by utilizing electrically neutral DNA probe in field-effect transistor measurements as evidenced by surface plasmon resonance imaging," Biosensors and Bioelectronics, vol. 41, pp. 795-801, 2013.

[95] G.-J. Zhang, J. H. Chua, R.-E. Chee, A. Agarwal, and S. M. Wong, "Label-free direct detection of MiRNAs with silicon nanowire biosensors," Biosensors and Bioelectronics, vol. 24, no. 8, pp. 2504-2508, 2009. 
[96] G.-J. Zhang, M. J. Huang, J. J. Ang, E. T. Liu, and K. V. Desai, "Self-assembled monolayer-assisted silicon nanowire biosensor for detection of protein-DNA interactions in nuclear extracts from breast cancer cell," Biosensors and Bioelectronics, vol. 26, no. 7, pp. 3233-3239, 2011.

[97] H. M. Lee, K. Lee, and S. W. Jung, "Multiplexed detection of protein markers with silicon nanowire FET and sol-gel matrix," in Proceedings of the 34th Annual International Conference of the IEEE EMBS, San Diego, Calif, USA, 2012.

[98] G. J. Zhang, M. J. Huang, J. A. Ang et al., "Label free detection of carbohydrate-protein interaction using nanoscale field-effect transistor biosensors," Analytical Chemistry, vol. 85, pp. 43924397, 2013.

[99] J. Y. Wu, C. L. Tseng, Y. K. Wang, Y. Yu, K. L. Ou, and C. C. $\mathrm{Wu}$, "Detecting interleukin-1b genes using a $\mathrm{N}_{2} \mathrm{O}$ plasma modified silicon nanowire biosensor," Journal of Experimental and Clinical Medicine, vol. 5, pp. 12-16, 2013.

[100] F. Shen, J. Wang, Z. Xu et al., "Rapid flu diagnosis using silicon nanowire sensor," Nano Letters, vol. 12, pp. 3722-3730, 2012.

[101] W. E. Svendsen, M. Jørgensen, L. Andresen et al., "Silicon nanowire as virus sensor in a total analysis system," in Proceedings of the 25th Eurosensors Conference, pp. 288-291, Athens, Greece, September 2011.

[102] X. Bi, A. Agarwal, and K.-L. Yang, "Oligopeptide-modified silicon nanowire arrays as multichannel metal ion sensors," Biosensors and Bioelectronics, vol. 24, no. 11, pp. 3248-3251, 2009.

[103] L. Luo, J. Jie, W. Zhang et al., "Silicon nanowire sensors for $\mathrm{Hg}^{2+}$ and $\mathrm{Cd}^{2+}$ ions," Applied Physics Letters, vol. 94, no. 19, Article ID 193101, 2009. 

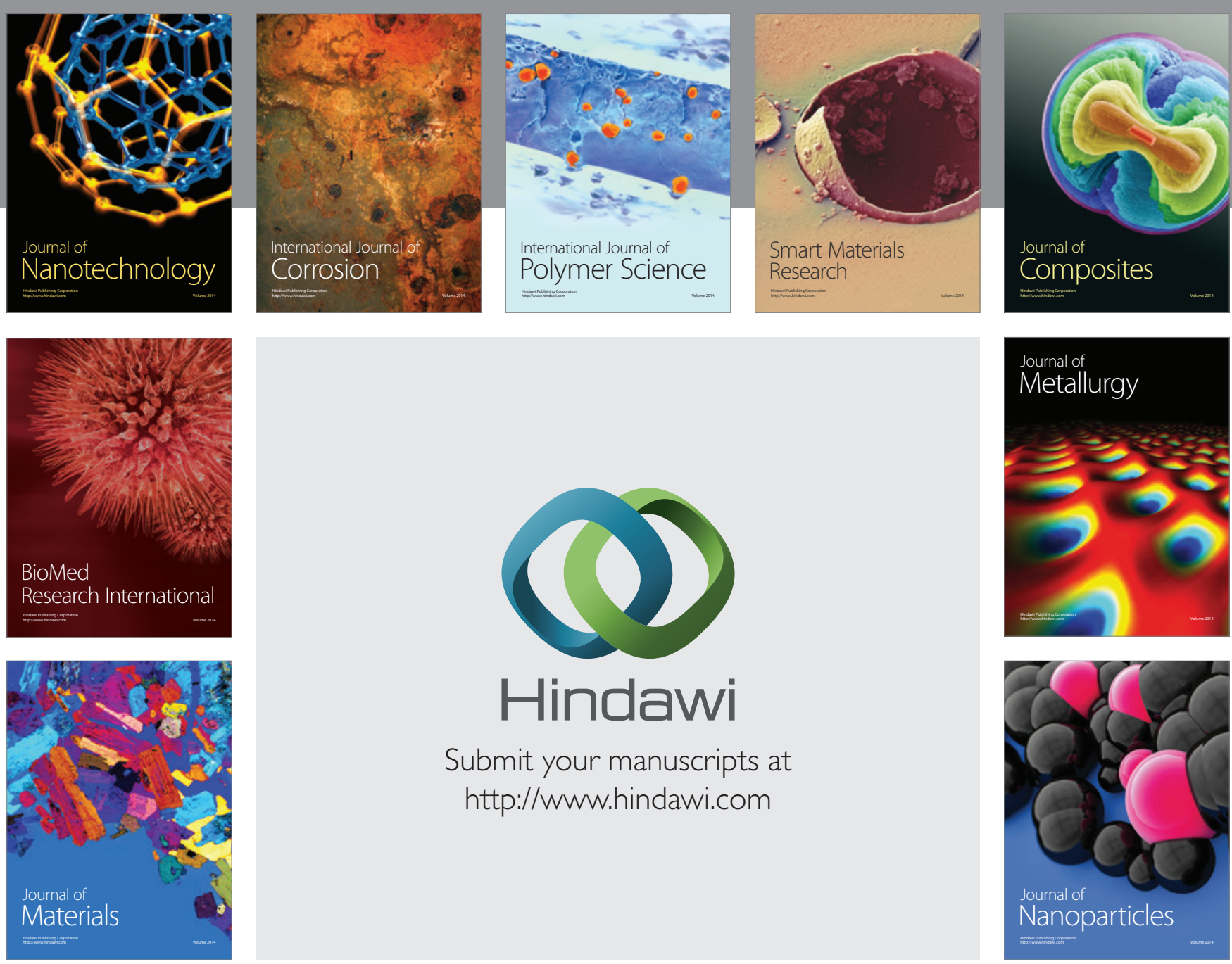

Submit your manuscripts at http://www.hindawi.com
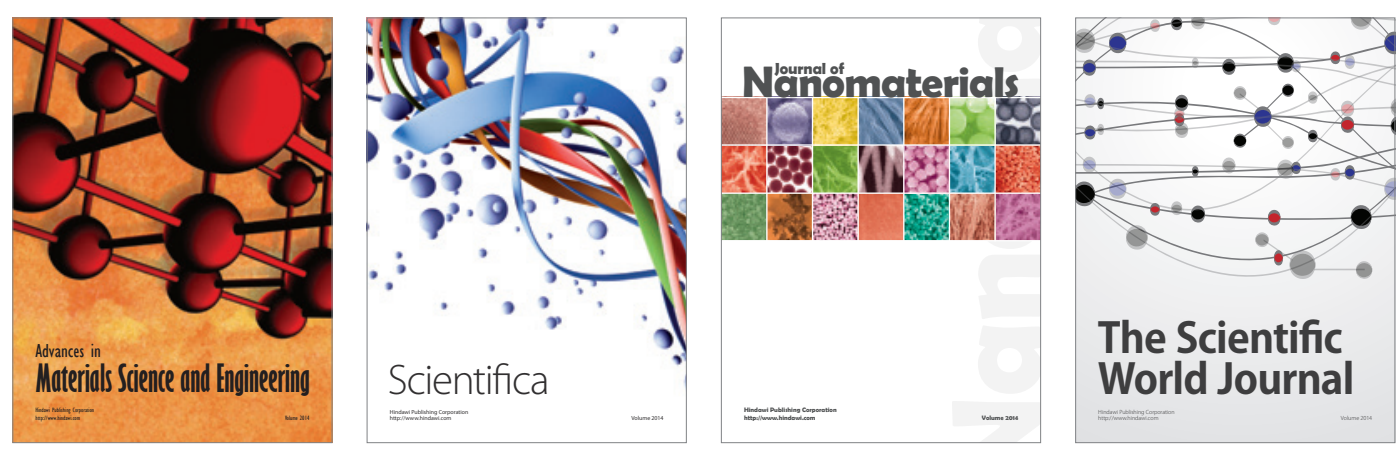

\section{The Scientific World Journal}
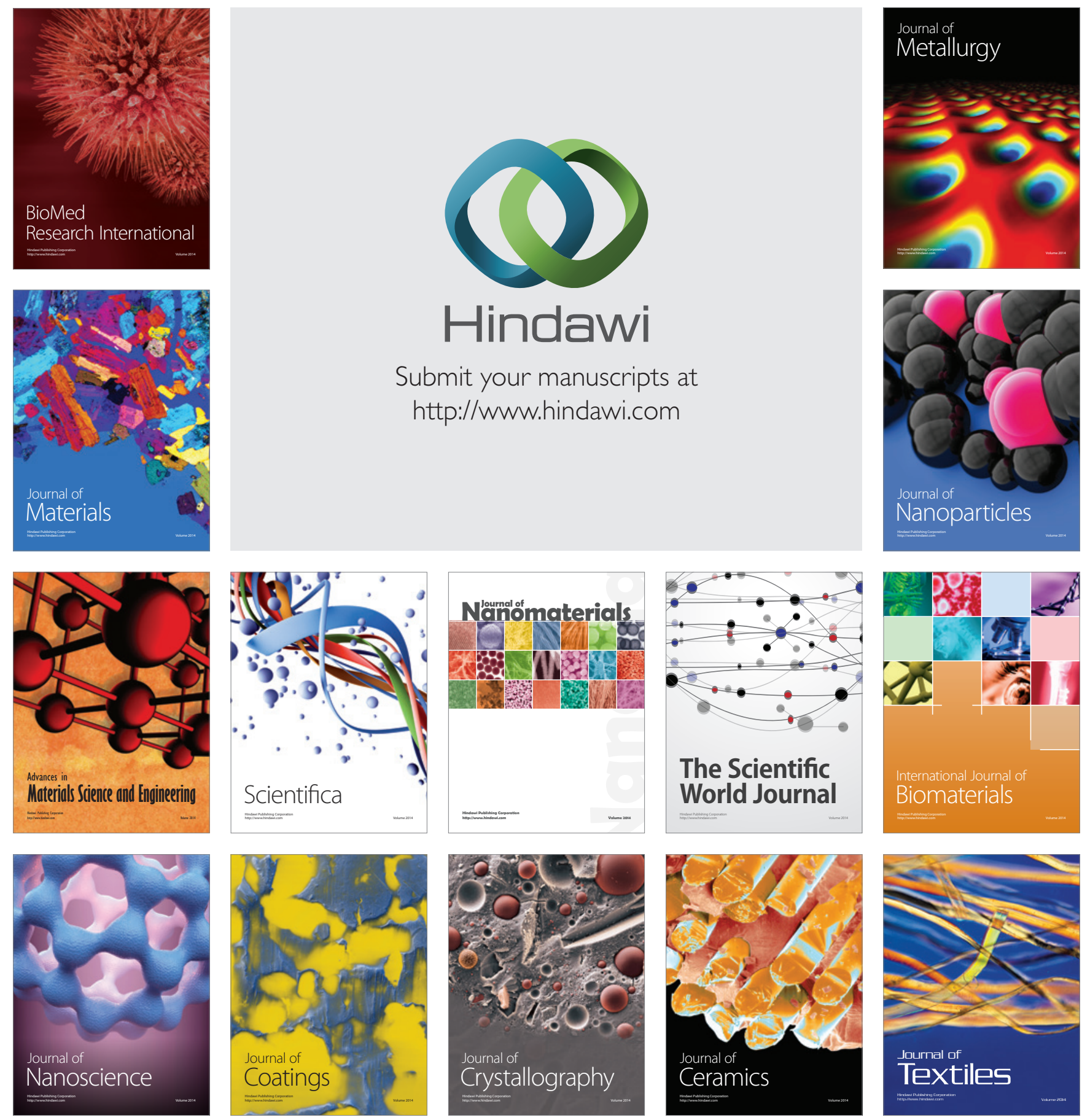